Carolina Maria do Carmo Alonso

\title{
O trabalho e o trabalhar de uma equipe de reabilitação no Programa Saúde da Família do município de São Paulo
}

Dissertação apresentada à Faculdade de Medicina da Universidade de São Paulo para obtenção do título de Mestre em Ciências

Área de concentração: Movimento, Postura e Ação Humana

Orientadora: Profa Dra Selma Lancman

São Paulo 
Esta dissertação está de acordo com as seguintes normas, em vigor no momento desta publicação:

Referências: Adaptado do International Committee of Medical Journals Editors (Vancouver)

Universidade de São Paulo. Faculdade de Medicina. Serviço de Biblioteca e Documentação. Guia de apresentação de dissertações, teses e monografias. Elaborado por Anneliese Carneiro da Cunha, Maria Julia de A. L. Freddi, Maria F. Crestana, Marinalva de Souza Aragão, Suely Campos Cardoso, Valéria Vilhena. $2^{a}$ ed. São Paulo: Serviço de Biblioteca e Documentação; 2005.

Abreviatura dos títulos dos periódicos de acordo com List of journals Indexed in Index Medicus. 
Dedico este trabalho aos meus irmãos, Ivany e Marco, porque sem eles eu não teria chegado até aqui. E, também, ao Marcelo, a Mariana e a Beatriz. Porque com eles eu cheguei até aqui. 


\section{Esta Velha}

Esta velha angústia,

Esta angústia que trago há séculos em mim,

Transbordou da vasilha,

Em lágrimas, em grandes imaginações,

Em sonhos, em estilo de pesadelo sem terror,

Em grandes emoções súbitas sem sentido nenhum.

Transbordou.

Mal sei como conduzir-me na vida

Com este mal-estar a fazer-me pregas na alma!

Se ao menos endoidecesse deveras!

Mas não: é este estar entre,

Este quase,

Este pode ser que...,

Isto. Um internado num manicômio é, ao menos, alguém,

Eu sou um internado num manicômio sem manicômio.

Estou doido a frio,

Estou lúcido e louco,

Estou alheio a tudo e igual a todos:

Estou dormindo desperto com sonhos que são loucura

Porque não são sonhos.

Estou assim...

Pobre velha casa da minha infância perdida!

Quem te diria que eu me desacolhesse tanto!

Que é do teu menino? Está maluco.

Que é de quem dormia sossegado sob o teu teto provinciano?

Está maluco.

Quem de quem fui? Está maluco.

Hoje é quem eu sou.

Se ao menos eu tivesse uma religião qualquer!

Por exemplo, por aquele manipanso

Que havia em casa, lá nessa, trazido de África.

Era feiíssimo, era grotesco,

Mas havia nele a divindade de tudo em que se crê.

Se eu pudesse crer num manipanso qualquer -

Júpiter, Jeová, a Humanidade -

Qualquer serviria,

Pois o que é tudo senão o que pensamos de tudo?

Estala, coração de vidro pintado!

Fernando Pessoa na voz de Álvaro de Campos. 


\section{AGRADEÇO:}

Aos profissionais da equipe de reabilitação que prestaram seu depoimento para esta pesquisa: Muito Obrigada.

Ao Marcelo, por ser meu companheiro nessa jornada, por me apoiar e me dar uma direção. Pela amizade, pelo cuidado, pelo carinho... (MUITO OBRIGADA!).

A Mariana, pela espera paciente pelo fim do mestrado da mãe dela.

A Selma, pela oportunidade de realizar este trabalho e tantos outros nos últimos anos.

A Márcia, pela inspiração e generosidade em me socorrer sempre que precisei do seu apoio.

A Maria, pelo incentivo, pelos "cafés filosóficos" e, sobretudo, pela amizade.

A Bia, por me ouvir e pela competência na organização da secretaria de pós-graduação do departamento.

Aos meus sogros, pela ajuda no cuidado das minhas filhas durante a realização desse trabalho.

A Angélica, queridíssima, pela disponibilidade.

A Thaís Laranjo, por ser minha amiga qualificada e me ouvir nos momentos de desespero.

A Eline pela ajuda na tradução do resumo. 


\section{SUMÁRIO}

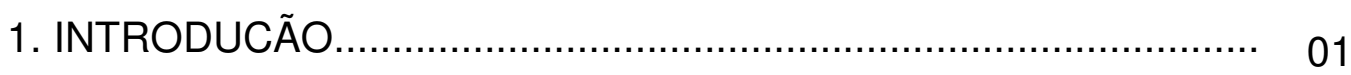

1.1 ATENÇÃO À SAÚDE DA PESSOA COM DEFICIÊNCIA............. 06

1.1.1 APONTAMENTOS SOBRE A DEFICIÊNCIA E A

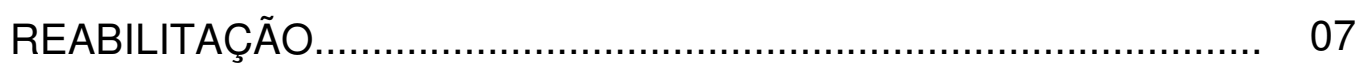

1.1.2 A ATENÇÃO À PESSOA COM DEFICIÊNCIA NO BRASIL E SEUS SERVIÇOS ............................................................................. 11

1.2 ATENÇÃO PRIMÁRIA À SAÚDE .............................................. 16

1.2.1 HISTÓRICO DA ATENÇÃO PRIMÁRIA À SAÚDE................... 17

1.2.2 ATENÇÃO PRIMÁRIA À SAÚDE: CONCEITO E CARACTERÍSTICAS.................................................................... 18

1.2.3 ATENÇÃO PRIMÁRIA NO BRASIL: UM RECORTE PARA O PROGRAMA SAÚDE DA FAMÍLIA................................................. 20

1.3 ARTICULANDO DOIS UNIVERSOS: A INCLUSÃO DA EQUIPE DE ATENÇÃO À SAÚDE DA PESSOA COM DEFICIÊNCIA NO PSF DA CIDADE DE SÃO PAULO ............................................... 28

1.3.1 A EQUIPE DE ATENÇÃO À SAÚDE DA PESSOA PORTADORA DE DEFICIÊNCIA (EASPPD): HISTÓRICO E

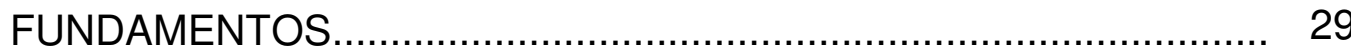

2. APORTE TEÓRICO ……................................................. 31

2.1 INTRODUÇÃO AO CAMPO DE ESTUDO DA PRODUÇÃO NO SETOR DE SERVIÇOS................................................................... 32

2.1.1 DEFINIÇÃO DE SERVIÇO................................................. 32

2.1.2 O CONCEITO DO SERVIÇO................................................. 35

2.1.3 AVALIAÇÃO DO VALOR DO SERVIÇO................................ 37

2.1.4 CARACTERÍSTICAS FUNDAMENTAIS DA OPERAÇÃO DE 
SERVIÇOS.

2.1.5 CLASSIFICAÇÃO DE SERVIÇOS......................................... 45

2.1.6 SERVIÇOS PROFISSIONAIS EM DETALHES........................ 46

2.1.7 SERVIÇO PÚBLICO: DEFINIÇÃO E CARACTERÍSTICAS....... 49

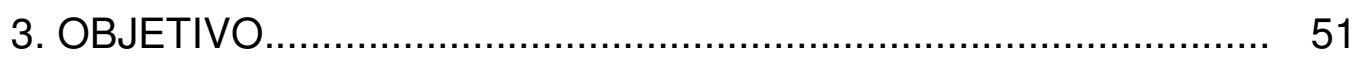

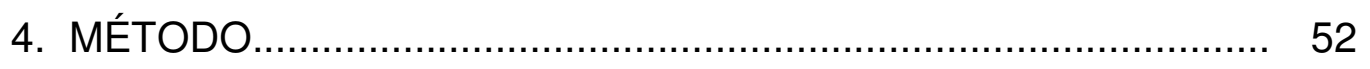

4.1 DESENHO DA PESQUISA .................................................. 53

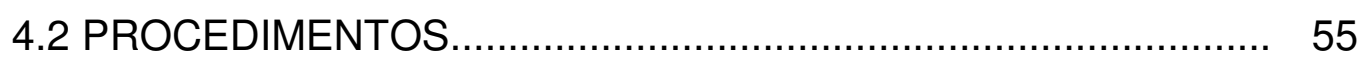

4.3 ANÁLISE DOS RESULTADOS E ELABORAÇÃO DO RELATO DO ESTUDO DE CASO DA EASPPD.......................................... 59

4.4 PROCEDIMENTOS ÉTICOS.................................................. 60

5. RESULTADOS

5.1 CONHECENDO O SERVIÇO DA EASPPD ................................... 62

5.2 O SERVIÇO NA PERSPECTIVA DE SEUS ATORES: ANÁLISE DO CONTEÚDO DAS ENTREVISTAS........................................... 72

5.2.1 A DUALIDADE DO SERVIÇO.............................................. 73

5.2.2 A INVISIBILIDADE DO TRABALHO ..................................... 75

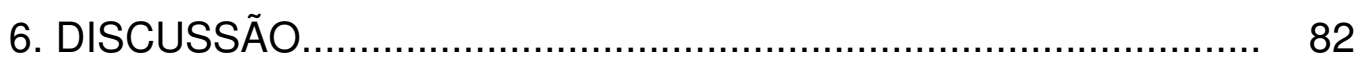

6.1 A OPERACIONALIZAÇÃO DO CONCEITO DO SERVIÇO DA EASPPD: A IDÉIA TRANSFORMADA EM AÇÃO............................. 83

6.1.1 O SERVIÇO DA EASPPD NA LINHA DO TEMPO.................. 86

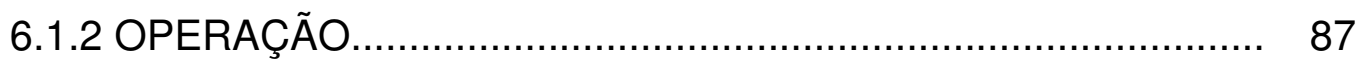

7. CONSIDERAÇÕES FINAIS..................................................... 89

8. REFERÊNCIAS BIBLIOGRÁFICAS........................................ 92 


\section{LISTA DE FIGURAS}

Figura 1 - Linha do tempo: Percurso das políticas públicas de atenção à pessoa com deficiência no município de São Paulo. Elaborado pelo autor com base em: Almeida (2000) e Ho e Oliver (2005)

Figura 2 - Localização do Distrito Paulistano de Vila Curuçá (adaptado de:

http://pt.wikipedia.org/wiki/Vila Curu\%C3\%A7\%C3\%A1 e http://www2.prefeitura.sp.gov.br/subprefeituras/spit/mapas/0003)...... 62

Figura 3. Fluxo de atendimento da EASPPD. (elaborado pelo autor).. 70 


\section{LISTA DE TABELAS}

Tabela 1 - Eixos da CIDID (elaborado pelo autor)

Tabela 2 - Principais diferenças na operação de serviços de reabilitação nos modelos Biomédico e de RBC. Elaborado pelo autor

Tabela 3 - Fontes de dados utilizados no estudo (elaborado pelo autor)......

Tabela 4 - Detalhamento das ações da EASPPD nas três esferas do serviço. (elaborado pelo autor) 


\section{LISTA DE SIGLAS}

$\begin{array}{ll}\text { ACS } & \text { Agente Comunitário de Saúde } \\ \text { APS } & \text { Atenção Primária à Saúde } \\ \text { EASPPD } & \text { Equipe de Atenção à Saúde da Pessoa Portadora de Deficiência } \\ \text { IDH } & \text { Índice de Desenvolvimento Humano } \\ \text { MS } & \text { Ministério da Saúde } \\ \text { OMS } & \text { Organização Mundial da saúde } \\ \text { ONU } & \text { Organização das Nações Unidas } \\ \text { OPAS } & \text { Organização Panamericana da Saúde } \\ \text { PAMPD } & \text { Programa de Ação Mundial para Pessoas Deficientes } \\ \text { PSF } & \text { Programa Saúde da Família } \\ \text { RBC } & \text { Reabilitação Baseada na Comunidade } \\ \text { SES } & \text { Secretaria Estadual da saúde de São Paulo } \\ \text { SMS } & \text { Secretaria Municipal da Saúde de São Paulo } \\ \text { SUS } & \text { Sistema Único de Saúde } \\ \text { UBS } & \text { Unidade Básica de Saúde } \\ \text { USF } & \text { Unidade de Saúde da Família }\end{array}$




\section{RESUMO}

Alonso CMC. O trabalho e o trabalhar de uma equipe de reabilitação do Programa Saúde da Família do município de São Paulo [dissertação]. São Paulo: Faculdade de Medicina, Universidade de São Paulo; 2009.

INTRODUÇÃO: A atuação de uma equipe de reabilitação junto à Estratégia Saúde da Família (PSF), iniciada na cidade de São Paulo no ano de 2001, inaugura um serviço singular de atenção a pessoas com deficiência na atenção básica. Tal projeto tem como objetivo estabelecer uma cultura de defesa dos direitos da pessoa com deficiência na busca do desmonte dos processos de exclusão social, construindo intervenções que articulem a prevenção de deficiências, reabilitação e educação por meio de ações intersetoriais (Fichino et al, 2008). Essa pesquisa visa conhecer e analisar aspectos da organização do trabalho desse serviço, à luz de aspectos do referencial teórico da gestão da operação de serviços. MÉTODO: Pesquisa qualitativa do tipo estudo de caso baseada nos princípios de Yin (2003) que combinou diferentes procedimentos de coleta de dados (pesquisa documental, entrevistas semi-estruturadas e aplicação de questionários). Foram realizadas sete entrevistas com trabalhadores de uma equipe de reabilitação no ano de 2007. Cada fonte de evidência recebeu tratamento diferenciado tendo em vista a finalidade de sua utilização e posteriormente foi realizado um diálogo dos resultados obtidos para construção de uma cadeia de evidências sobre a qual se construiu o estudo do caso. 
RESULTADOS: Foi verificado nesse estudo que o conceito do serviço pesquisado não se consolidou devido às mudanças nas políticas públicas de saúde que ancoravam essa experiência e a falhas no projeto do serviço, como por exemplo, o não detalhamento da organização do trabalho. Isso teve impacto para os trabalhadores que diante da fluidificação do conceito do serviço passam a organizar suas ações a partir de estratégias individuais ou de demandas pontuais se remetendo pouco aos pressupostos que fundamentam o serviço. Para os gestores tal quadro resulta na dificuldade de alinhar suas expectativas com o serviço realizado de fato. CONCLUSÃO: O hiato que existe entre a operação e o conceito precisa ser preenchido em duas vias: uma aproximando as proposições teóricas presentes no conceito do serviço da realidade cotidiana de quem desempenha o trabalho; e, na direção oposta, reforçando as premissas do projeto pelo refinamento e incorporação dessas pelos profissionais de linha de frente e gestores.

Descritores (DeCS): Gestão em Saúde, Serviços de Reabilitação, Programa Saúde da Família, Terapia Ocupacional. 


\section{SUMMARY}

Alonso CMC. Work and working in a rehabilitation team from the Family Health Program in São Paulo City [dissertation]. São Paulo: Faculdade de Medicina, Universidade de São Paulo; 2009.

The performance of a rehabilitation team together with the Family Health Program (FHP), begun in the city of São Paulo in 2001, launches a unique service to attend people with deficiencies in primary care. Such service aims to establish a consciousness of protection of the rights of disabled people in order to dismantle the process of social exclusion by creating actions to promote the prevention of disabilities as well as education and rehabilitation through intersectorial interventions.

This research seeks to understand and analyze aspects of the work organization of this rehabilitation team based on the theoretical framework of the service operation management. METHODS: Qualitative research conducted by means of case study following Yin's principles (2003) which combined different procedures for data collection (desk research, semistructured interviews and questionnaires). Seven interviews were conducted with employees of a team of rehabilitation in 2007. Each source of evidence received a differentiated treatment according to the purpose of its use. And, later, the results obtained were compared for the construction of a chain of evidences on which a case study was built. RESULTS: It has been verified in this study that the concept of the service was not consolidated due to: 1 . 
changes in public health policies that anchored this experience; 2. flaws in the project of the service, such as, the lack of detailing the work organization. These results had an impact on the workers who, before the weakening of the concept of the service, began to base their actions on individual strategies or specific demands, referring very little to the directives that ground the service. For the managers such situation is result of a difficulty to align their expectation with the actual service. CONCLUSION: The gap that exists between the operation and the concept needs to be completed in a two-way street. One way, approaching the theoretical propositions in the concept of the service from the daily reality of who performs the work. And, on the other way, reinforcing the premises of the project by the refinement and incorporation of the front-line professionals and managers.

Key words: Health Management, Rehabilitations Servicies, Family Health Program, Occupational Therapy, Public Health Administration 


\section{INTRODUÇÃO}

Os serviços de assistência à pessoa com deficiência, no Brasil, se constituem, predominantemente, por entidades de caráter filantrópico e por estabelecimentos ligados a instituições de ensino (Almeida 1997, 2000; Almeida e Campos, 2002, Nallin, 1992; Oliver, 1998; Oliver et al, 2001), os quais operam por meio de frágil integração com outros programas de saúde ou de setores como, por exemplo, os da educação e promoção social, o que dificulta o alinhamento de suas práticas com as políticas públicas de saúde instituídas para a população em geral (Oliver, 1998; Oliver et al, 1999).

Esses serviços, em sua maioria, são grandes centros especializados, que têm no restabelecimento da função física o objetivo final do processo de reabilitação. Os demais problemas enfrentados pela pessoa com deficiência, como limitações no desempenho de atividades e restrições na participação social, são considerados como decorrentes da alteração bio-patológica (Almeida 1997, 2000; Oliver et al 2001).

Como conseqüência desta configuração, foi verificada uma disparidade entre as ações planejadas e desenvolvidas pelos centros especializados de reabilitação e as necessidades de saúde da população com deficiência.

Tal fato resultou numa problemática discutida por Almeida $(1997,2000)$, Oliver (1998) Oliver et al (1999, 2001, 2003), Rocha (1997), dentre outros autores, que vai além da qualificação dos serviços prestados nessas instituições, e aponta, também, para o questionamento da 
capacidade de atendimento, por esses serviços, das demandas da população com deficiência no âmbito da cobertura, universalidade e integralidade ${ }^{1}$.

Para o enfrentamento dessa situação, houve a busca de alternativas ao modelo assistencial de reabilitação tradicional, organizado em torno dos grandes centros especializados.

Essa busca foi impulsionada por movimentos sociais, compostos de pessoas com deficiência e profissionais de reabilitação (Almeida, 2000), que estavam inseridos no cenário de proposições internacionais como as do Programa de Ação Mundial para Pessoas Deficientes (PAMPD - ONU, 1982) e da Reforma Sanitária Brasileira².

$\mathrm{Na}$ direção de redefinir as ações de assistência à população com deficiência, no Brasil, a criação de serviços integrados com as políticas públicas de saúde foi um passo estratégico porque, por um lado, coadunava com os princípios do sistema de saúde, que estava em construção, para a população em geral, e, por outro, colocava as questões da população com deficiência na esfera da cidadania e não mais da filantropia.

\footnotetext{
1 Universalidade e Integralidade são dois princípios do sistema de saúde brasileiro que se originaram no bojo do movimento sanitário e que significam:

Universalidade: todas as pessoas têm o direito ao atendimento no SUS brasileiro e estas serão atendidas conforme as suas necessidades.

Integralidade: considerar a pessoa como um todo, atendendo a todas as suas necessidades. Por isso, busca-se integrar as ações de promoção, prevenção, tratamento e reabilitação e promover a articulação destas com outras políticas públicas.

Disponível em: http://www.opas.org.br/observatorio/principal.cfm?hobsnumcod=19 acessado em 05.02.2008

${ }^{2}$ Reforma Sanitária: Movimento de profissionais de saúde das décadas de 1970/80 que apresentava um conjunto de idéias em relação às mudanças e transformações necessárias na área da saúde. Essas mudanças não abarcavam apenas o sistema, mas todo o setor de saúde, introduzindo uma nova idéia, na qual o resultado final era entendido como a melhoria das condições de vida da população. Disponível em: http://bvsarouca.cict.fiocruz.br/sanitarista05.html acessado em 10.10.2007.
} 
Nesse sentido, o Estado de São Paulo sai na frente do resto do País, implementando experiências de reabilitação no setor público, inclusive em atenção primária, fato até então inédito, ainda na década de 1980 (Almeida, 2000).

Esse cenário, aliado às peculiaridades de implantação do Programa Saúde da Família (PSF) na cidade de São Paulo ${ }^{3}$, propiciaram a inclusão da Equipe de Atenção à Saúde da Pessoa Portadora de Deficiência (EASPPD) em algumas equipes do PSF do município (Rocha e Kretzer, 2000; Rocha et al, 2002).

A importância desta experiência deve-se ao fato de aliar ao PSF - que é apontado pelo Ministério da Saúde (MS) como a principal estratégia de reorientação das práticas assistenciais em saúde da população brasileira na atualidade (Brasil, 2001) - ao atendimento das demandas da população com deficiência.

E, considerando as propostas atuais do MS de implementação dos Núcleos de Apoio à Saúde da Família (NASF), que irão expandir nacionalmente a incorporação de profissionais de reabilitação junto ao PSF, o desenvolvimento de pesquisas que discutam as experiências de natureza semelhante ferta de subsídios que corroborem com a implementação de serviços correlatos em outros contextos.

Nessa direção, esta dissertação buscará conhecer a organização do trabalho da EASPPD, partindo da identificação do conceito do serviço ${ }^{4}$ presente em seu projeto de implantação denominado: Programa de atenção

${ }^{3} \mathrm{~A}$ implantação do PSF na cidade de São Paulo será apresentada no item 2.1.1 deste capítulo.

${ }^{4}$ As definições de conceito e valor de serviço serão abordadas no Aporte Teórico deste estudo. 
à saúde da pessoa portadora de deficiência e incapacidade no PSF/QUALIS - SP. Zona leste e sudeste do município de São Paulo (ROCHA E KRETZER, 2000). Outrossim, buscará conhecer aspectos do trabalhar nesse serviço a partir do depoimento dos seus trabalhadores.

Posteriormente, será construído um diálogo, entre o conceito do serviço e a análise das entrevistas realizadas com os profissionais da EASPPD no intuito de verificar as tangências, incongruências e discrepâncias que possam existir entre o projeto do serviço e sua operação.

A esse respeito, Silva (2007) afirma que a análise da concepção dos serviços e do seu valor permite tanto entender a implantação de sistemas de serviços, como o processo em que modelos concebidos em uma esfera abstrata (como um conceito) são transformados em ações e resultam em serviço para o usuário.

Para atender a esses propósitos, neste capítulo serão apresentados alguns temas importantes para apreensão da problemática abordada por esse estudo que foram sistematizados a partir de dois eixos:

- a ATENÇÃo a Saúde da PESSOA COM DEFICIÊNCIA.

- A ATENÇÃo PRIMÁRIA À SAÚdE: RECORTE PARA O PROGRAMA SAÚDE DA FAMÍLIA.

No que se refere ao campo de atenção à saúde da população com deficiência serão apresentados os conceitos de deficiência e reabilitação, bem como, a evolução histórica dos sistemas de classificação da deficiência 
na tentativa de delinear, a partir desses conceitos, a caracterização dos serviços de atenção a pessoa com deficiência no cenário brasileiro.

Quanto a Atenção Pimária à Saúde (APS), primeiramente se fará uma breve introdução sobre a natureza da APS com a apresentação do seu histórico, definição e características.

Em seguida, apresentar-se-á uma visão geral dos objetivos, características e operação do Programa Saúde da Família (PSF) - que é a estratégia ao redor da qual se organiza a APS no Brasil - bem.como, uma descrição sucinta do processo de implantação desse programa na cidade de São Paulo.

O último tópico deste capítulo se constrói na confluência dos temas apresentados para contextualizar a implantação da EASPPD na cidade de São Paulo. 


\subsection{ATENÇÃO À SAÚDE DA PESSOA COM DEFICIÊNCIA.}

De acordo com o MS a atenção à saúde da pessoa com deficiência pressupõe, além do cuidado aos agravos e doenças comuns a qualquer cidadão, a existência de serviços que cuidem estritamente das especificidades relativas à deficiência (Brasil, 2006b) os quais são conhecidos como serviços de reabilitação.

Reabilitação significa, usualmente, o ato de re-habilitar, ou seja, de tornar habilitado novamente algo ou alguém que estaria desabilitado, inapto. No entanto, no campo da atenção à saúde da pessoa com deficiência, o termo reabilitação apresenta o desafio de traduzir um conjunto de modelos assistenciais $^{5}$ que possuem objetivos diferentes como resultado final do processo de reabilitação.

Essa diferença relativa aos objetivos propostos em diferentes modelos de assistência se deve, em grande parte, à concepção que os serviços têm do fenômeno da deficiência. Nessa direção, cada modelo assistencial irá apresentar projetar seus serviços de maneira singular.

Portanto, para favorecer a compreensão sobre a configuração dos serviços de reabilitação serão apresentadas as diferentes concepções do fenômeno da deficiência, abordadas a partir da apresentação da evolução

\footnotetext{
${ }^{5}$ Modelo assistencial: Segundo Teixeira (2000, p.161) é definido como "Combinações de saberes (conhecimentos) e técnicas (métodos e instrumentos) utilizados para resolver problemas e atender necessidades individuais e coletivas".
} 
dos seus modelos de classificação, e, o reflexo dessas concepções na constituição dos serviços de assistência a pessoa com deficiência no Brasil.

\subsubsection{APONTAMENTOS SOBRE A DEFICIÊNCIA E A REABILITAÇÃO.}

Existe uma dificuldade em definir o que é deficiência, já que esta, muitas vezes, não pode ser observada diretamente, sendo inferida por meio de causas presumidas (prejuízos ou danos), com suas conseqüências refletidas na restrição ou incapacidade para o desempenho de atividades (auto-cuidado, lazer, trabalho) (Di Nubila e Buchalla, 2008).

Isso porque, embora os danos à saúde, que causam a deficiência, necessitem de avaliação médica, sua certificação clínica, apesar de indispensável, não é suficiente, na maioria dos casos, para atestar a incapacidade (Farias e Buchalla, 2005).

Diante disso, é presumível que a definição do que é a deficiência não se faça de maneira estanque, mas sempre relacionada às suas causas e conseqüências de forma dinâmica.

Na tentativa de uniformizar a compreensão sobre esse fenômeno (deficiência) a OMS propôs sistemas de classificação os quais serão apresentados adiante. 


\subsubsection{A EVOLUÇÃo dOS SISTEMAS DE CLASSIFICAÇÃO DA DEFICIÊNCIA}

Na perspectiva de equacionar as conseqüências do adoecimento, em 1976 a Organização Mundial da Saúde (OMS) publicou a International Classification of Impairment, Disabilities and Handcaps (ICIDH), traduzida para o português como Classificação Internacional das Deficiências, Incapacidades e Desvantagens (CIDID) que apresenta os seguintes conceitos (Farias e Buchalla, 2005):

- Deficiência: é uma perda ou anomalia da função psicológica, fisiológica ou anatômica.

- Incapacidade: é uma conseqüência da deficiência no desempenho das atividades.

- Desvantagem: reflete as condições de adaptação do indivíduo ao meio ambiente como uma resultante da deficiência e da incapacidade.

O modelo proposto pela CIDID descreve de maneira linear, as condições decorrentes de uma doença como exemplificado na Tabela 1:

Esse modelo contribuiu para uma compreensão mais abrangente do processo de incapacidade. No entanto, foi alvo de críticas em decorrência de suas limitações em explicar os fenômenos de funcionalidade e de incapacidade humana (Sampaio et al, 2005). 


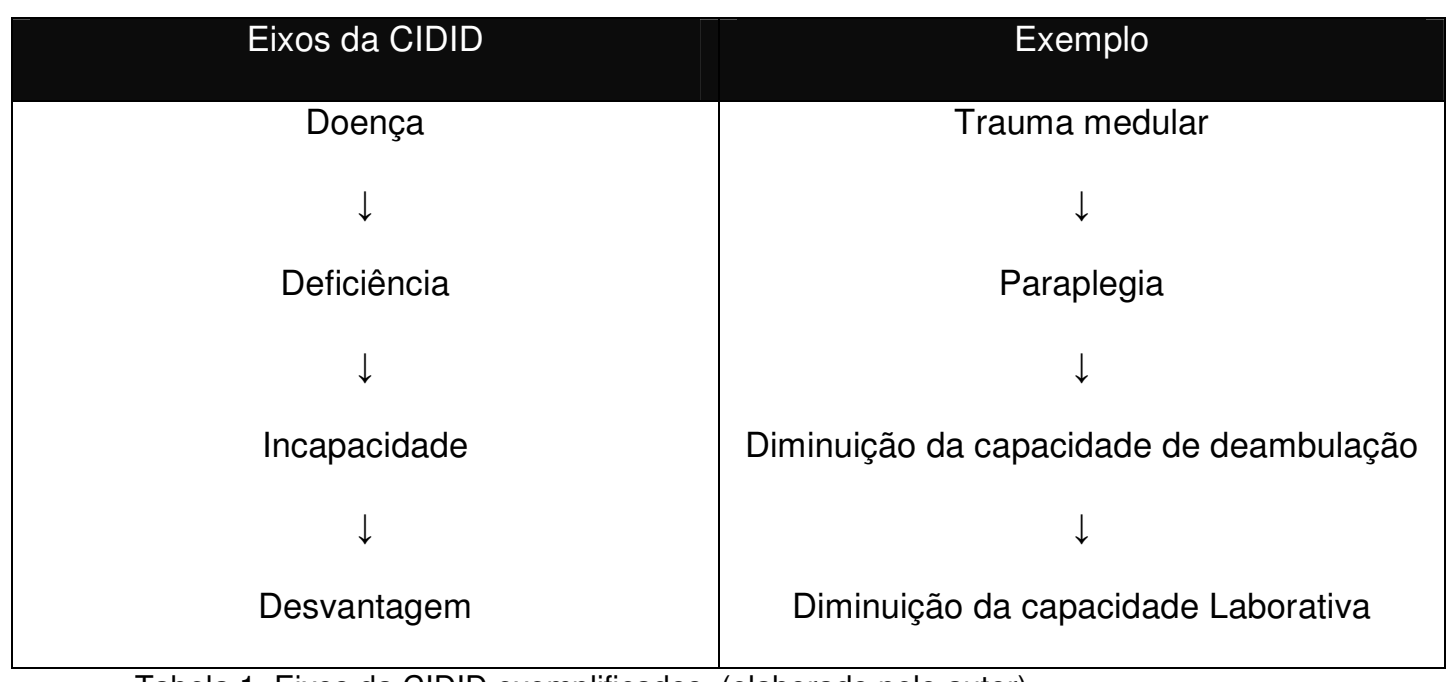

Tabela 1. Eixos da CIDID exemplificados. (elaborado pelo autor).

Uma das críticas feitas à CIDID refere-se ao fato de que suas classificações estavam alinhadas com as conseqüências das doenças descrevendo apenas os aspectos negativos das condições de saúde (Sampaio et al, 2005).

Além disso, o modelo causal de progressão linear das disfunções para as incapacidades e as restrições sociais apresentava problemas para classificar os diversos aspectos da funcionalidade (Almeida, 2000; Sampaio et al, 2005).

Em 2000, após diversas revisões, foi aprovada a CIDID-2 que passou a adotar o modelo biopsicossocial, uma síntese das abordagens, médica e social, ao processo de incapacidade.

As três dimensões descritas previamente na CIDID passaram a ser definidas como: disfunção, limitação de atividade e restrição da participação. Esses domínios apresentam a mesma significância e são independentes uns dos outros no processo de incapacidade (OMS, 2000) 
Por exemplo, uma pessoa que apresenta uma disfunção não necessariamente terá limitações de atividade ou restrições na participação social, igualmente, uma pessoa pode vivenciar limitações de atividade e restrição na participação sem apresentar nenhuma disfunção (Sampaio et al, 2005)

Esse sistema de classificação foi substituído definitivamente em 2001 quando a Assembléia Mundial de Saúde aprovou a International Classification of Functioning Disability and Health (ICF) que em português foi traduzida como a Classificação Internacional de Funcionalidade (CIF) (Farias e Buchalla, 2005).

A CIF se constrói ao redor do termo da funcionalidade que abrange os seguintes componentes (OMS, 2003):

- Estruturas do corpo: são partes anatômicas do corpo tais como órgãos, membros e seus componentes.

- Funções: são as funções fisiológicas ou psicológicas dos sistemas corporais

- Atividade e participação social: é a execução de uma tarefa ou ação por um indivíduo. Participação é o ato de se envolver em uma situação vital.

- Fatores ambientais: constituem o ambiente físico, social e de atitudes em que as pessoas vivem e conduzem sua vida.

Nesse modelo cada nível de avaliação se relaciona de forma dinâmica com os demais, sendo todos influenciados pelos fatores 
ambientais. A funcionalidade é usada no aspecto positivo e o aspecto negativo corresponde à incapacidade.

Para o sistema CIF, as deficiências podem ser parte ou expressão de uma condição de saúde, mas não indicam necessariamente a presença de uma doença. Ter uma deficiência não implica que o indivíduo seja uma pessoa doente (OMS, 2003).

No que se refere à incapacidade, para o sistema CIF, esta é resultante da interação entre a disfunção apresentada pelo indivíduo (seja orgânica e/ou da estrutura do corpo), a limitação de suas atividades e a restrição na participação social, e, ainda, dos fatores ambientais sendo que estes últimos podem atuar como facilitadores ou barreiras para 0 desempenho da atividade e participação (OMS, 2003).

\subsubsection{A ATENÇÃO À PESSOA COM DEFICIÊNCIA NO BRASIL E SEUS SERVIÇOS.}

Os serviços de assistência à pessoa com deficiência, no Brasil, se constituem, predominantemente, por entidades de caráter filantrópico e por estabelecimentos ligados a instituições de ensino (Almeida 1997, 2000; Almeida e Campos, 2002, Nallin, 1992; Oliver, 1998; Oliver et al, 2001), os quais operam por meio de frágil integração com outros programas de saúde ou de setores como, por exemplo, os da educação e assistência social.

Esses serviços, em sua maioria, são grandes centros especializados, que buscam como resultado final do processo de reabilitação o 
restabelecimento da função tendo como foco das intervenções as estruturas do corpo afetadas por danos.

O processo de operação desse tipo de serviço se caracteriza pela soma de intervenções realizadas com recursos de alta densidade tecnológica, aplicados por diferentes profissionais (Almeida, 1997, 2000; Almeida e Campos, 2002; Nallin, 1992; Oliver et al 1999).

As ações propostas pelos centros especializados de reabilitação são pacotes fechados, que segundo Almeida (2000), estruturam -se a partir de procedimentos-padrão definidos previamente como parte inflexível da organização do trabalho institucional.

Isso contribui na determinação de critérios rígidos para a seleção dos usuários que acessarão o serviço. Isso porque serão elegíveis apenas os usuários cujas necessidades podem ser atendidas pelo pacote de ações previamente estabelecidas pelo serviço de reabilitação.

A esse respeito, Almeida (2000, p. 90) escreveu:

(...) criar soluções é quase impraticável, na medida em que, do paciente, só se visualizam os problemas definidos antes de sua chegada, que são aqueles cujas supostas soluções já se encontram estruturadas, do ponto de vista da organização do trabalho.

Outra questão importante a ser considerada a respeito dos serviços prestados pelos centros especializados de reabilitação, é o pressuposto de que a inclusão social da pessoa com deficiência se dá a partir do 
restabelecimento da função, por meio de uma intervenção focada no dano a estrutura do corpo. Tal pressuposição exclui do escopo do processo de reabilitação outras demandas, tais como: problemas sociais, econômicos e psicológicos (Almeida e Campos, 2002).

Nesse sentido, Almeida (1997) coloca que as dificuldades enfrentadas pela pessoa com deficiência no âmbito social ou econômico, por exemplo, são entendidas como questões que interferem no processo de reabilitação, e não como problemas decorrentes e/ou inerentes aos quadros de incapacidade.

Esse modo de organização dos serviços de reabilitação apresenta como conseqüência uma baixa cobertura assistencial decorrente, dentre outros fatores: do alto custo financeiro desses serviços, da dificuldade de acesso, já que estes serviços se localizam em grandes centros urbanos, e ainda, dos critérios rigorosos de elegibilidade dos usuários (Naalin, 1992; Almeida e Campos, 2002; Oliver et al 1999).

Tal fato resultou em uma problemática discutida por Almeida (1997,2000), Oliver (1998) Oliver et al (1999, 2001, 2003), Rocha (1997), que vai além da qualificação dos serviços prestados nessas instituições, e aponta, também, para o questionamento da capacidade de atendimento, por esses serviços, das demandas da população com deficiência no âmbito da cobertura, universalidade e integralidade.

Esse quadro deflagrou a necessidade de idealização de modelos alternativos de assistência. Nessa direção, modelos de base territorial, 
descentralizados, focados na comunidade ganham espaço no palco das discussões sobre a atenção à saúde da pessoa com deficiência dentre os quais se destaca a Reabilitação Baseada na Comunidade (RBC).

O principal mote desse modelo é a transferência, para a comunidade, dos recursos (humanos, financeiros, tecnológicos, etc.) despendidos com a reabilitação, no intuito de ampliar a cobertura da assistência à saúde da pessoa com deficiência, bem como, oferecer uma atenção que abarque além do restabelecimento das funções a diminuição de incapacidades.

A operação desses serviços deverá ser desenhada tendo como base as necessidades das pessoas com deficiência de um território e não apenas na aplicação de tecnologias específicas de reabilitação.

É importante que os serviços de RBC funcionem integrandos à rede de saúde local e de outros setores, como educação, cultura, etc. (OPAS apud Oliver et al 1999).

No que diz respeito aos resultados dos serviços, que operam no modelo de RBC, espera-se que: busquem soluções para problemas reais da população com deficiência e contribuam para o aumento da qualidade de vida da pessoa com deficiência, de sua família e da comunidade (OPAS apud Oliver et al 1999).

As críticas relacionadas à operação desse modelo referem-se à acentuada simplificação das ações de reabilitação, com possível substituição de profissionais por pessoas da comunidade, pela utilização dos serviços de saúde locais, que poderiam ficar sobrecarregados com o acúmulo de 
atribuições e, ainda, pela transferência da responsabilidade de cuidado da pessoa com deficiência para a comunidade, a qual, por sua vez, pode não estar disposta e/ou preparada para essa tarefa (Almeida, 2000, Oliver et al, 1999).

No cenário nacional, a RBC ganha espaço a partir da publicação do documento: "Atenção à Pessoa Portadora de Deficiência no Sistema Único de Saúde - Planejamento e Organização de Serviços" (Brasil, 1995) o qual se propõe a difundir e apoiar a implantação de programas de RBC, no Brasil, de forma integrada a rede de serviços de saúde.

Entretanto, a despeito dos incentivos do Ministério da Saúde para que estados e municípios adotassem os serviços de RBC como parte de um programa de fortalecimento da atenção à saúde da pessoa com deficiência, as experiências nesse sentido ainda são escassas ${ }^{6}$.

Até aqui foram apresentados os modelos de assistência à pessoa com deficiência que predominam no cenário nacional. Entretanto, vale ressaltar, que o serviço prestado pela EASPPD não se enquadra de forma estrita em nenhum desses modelos embora seu projeto, tangencie características de ambos.

Por conseguinte, para enriquecer análises posteriores sobre a EASPPD, foi elaborado um quadro resumo (Tabela 2), com as principais diferenças encontradas na operação dos serviços tradicionais de reabilitação e dos serviços de base territorial (RBC).

\footnotetext{
${ }^{6}$ Almeida (2000) apresenta relação detalhada das experiências de RBC desenvolvidas no Brasil, não foram encontrados dados sobre o quadro atual das experiência de RBC brasileiras.
} 


\begin{tabular}{|c|c|}
\hline MODELO TRADICIONAL & MODELO TERRITORIAL(RBC) \\
\hline $\begin{array}{l}\text { Ações centralizadas nas grandes } \\
\text { instituições de reabilitação }\end{array}$ & $\begin{array}{l}\text { Ações descentralizadas, permeando diferentes } \\
\text { níveis de atenção à saúde. }\end{array}$ \\
\hline $\begin{array}{l}\text { Poucos serviços alocados em grandes } \\
\text { centros urbanos }\end{array}$ & Diversos serviços distribuídos nas comunidades \\
\hline $\begin{array}{l}\text { Predomínio do uso de recursos } \\
\text { tecnológicos de alta complexidade: Ex. } \\
\text { Diagnóstico por imagem, aparelhos } \\
\text { ortopédicos, técnicas cirúrgicas, etc. }\end{array}$ & $\begin{array}{l}\text { Predomínio no uso de tecnologias centradas em } \\
\text { recursos humanos. Ex. Atendimentos } \\
\text { domiciliares, acolhimento, Fomento da rede de } \\
\text { suporte social, acompanhamento terapêutico. }\end{array}$ \\
\hline Foco no indivíduo & Foco na relação do indivíduo com seu território. \\
\hline $\begin{array}{l}\text { Seleção dos usuários para inclusão no } \\
\text { serviço }\end{array}$ & Acesso universal ao serviço \\
\hline $\begin{array}{l}\text { Programas padrão instituídos } \\
\text { previamente }\end{array}$ & $\begin{array}{l}\text { Programas baseados nas necessidades dos } \\
\text { usuários. }\end{array}$ \\
\hline $\begin{array}{l}\text { Restabelecimento da função como } \\
\text { objetivo do processo de reabilitação - } \\
\text { Foco na deficiência. }\end{array}$ & $\begin{array}{l}\text { Inserção social como objetivo do processo de } \\
\text { reabilitação - Foco na redução da incapacidade } \\
\text { com aumento da funcionalidade e da participação } \\
\text { social }\end{array}$ \\
\hline
\end{tabular}

Tabela 2 - Principais diferenças na operação de serviços de reabilitação nos modelos tradicionais e territoriais de reabilitação (Elaborado pelo autor).

\subsection{ATENÇÃO PRIMÁRIA À SAÚDE}

Neste tópico será realizada uma apresentação sucinta do histórico, definição e características da APS. Em seguida será apresentado o modelo de APS que vigora no Brasil desde 1994: O Programa Saúde da Família (PSF). 


\subsubsection{HISTÓRICO DA ATENÇÃO PRIMÁRIA À SAÚDE}

A Grã Bretanha, no ano de 1920, foi o primeiro país do mundo a organizar a oferta de serviços de saúde em três níveis hierarquizados e com funções definidas: centros de saúde primários, centros de saúde secundários e hospitais escola (Starfield, 2002).

A sistematização da Grã Bretanha serviu de base para a organização de serviços regionalizados e hierarquizados, cujos diferentes níveis de atenção apresentam responsabilidades distintas para responder às necessidades de saúde da população.

Esse arranjo teórico tornou-se referência para a reorganização dos serviços de saúde em vários países que passaram a adotar um nível de atenção médica primária identificável e em funcionamento (Starfield, 2002).

No ano de 1978 a OMS organizou a Conferência Internacional de Cuidados Primários à Saúde, em Alma-Ata, que definiu a meta de "Saúde para todos no ano 2000" a ser alcançada mediante o fomento da Atenção Primária à Saúde (Aleixo, 2002).

Os princípios dessa conferência foram enunciados em uma declaração (Declaração de Alma-Ata) que destacou elementos da APS que a OMS estava empenhada em difundir nesse momento: a integração dos serviços locais num sistema nacional, a participação social, a necessidade de ações intersetoriais, além, da relação da saúde com o desenvolvimento econômico e social. 
Esse discurso confirmará ao longo dessa década, de distintas maneiras e com distintos graus de intensidade, processos de reforma em países, com modelos de prestação de serviços diversos (Aleixo, 2002; Starfield, 2002; Conill, 2008).

\subsubsection{ATENÇÃo PRIMÁRIA À SAÚdE: CONCEITO E CARACTERÍSTICAS}

A atenção primária é a entrada para o sistema de saúde, bem como, é o nível de atenção que acolhe todas as condições, excetuando as muito raras e/ou complexas, de maneira longitudinal, com foco nas pessoas e não em suas enfermidades (Starfield, 2002).

Os serviços da atenção primária devem se localizar próximos de onde as pessoas vivem, coordenando ou integrando a rede de atenção em outros níveis de atenção à saúde (OMS, 1978; Starfield, 2000).

Segundo a declaração de Alma Ata (OMS, 1978) os componentes fundamentais da atenção primária são: educação em saúde; saneamento ambiental, especialmente de águas e alimentos; programas de saúde materno-infantis, inclusive imunizações e planejamento familiar; prevenção de doenças endêmicas locais; tratamento adequado de doenças e lesões comuns; fornecimento de medicamentos essenciais; promoção de boa nutrição; e medicina tradicional. 
De acordo com Starfield (2002) as principais características desse nível de atenção são:

- Enfoque na Saúde

- Ações de prevenção de agravos aliadas às medidas curativas

- Ações abrangentes que vão para além da queixa dos usuários

- Promoção da saúde

- Atenção Longitudinal

- Trabalho em equipe multiprofissional

- Colaboração intersetorial

- Participação da comunidade

- Responsabilização do usuário pela sua saúde

Em alguns países, como, Canadá, Cuba e Inglaterra, por exemplo, a APS foi organizada em torno da assistência à família. Tais experiências influenciaram a organização da APS no Brasil que, desde 1994, adotou o Programa Saúde da Família como a principal estratégia de reorganização, não apenas da APS, mas de todo o modelo assistencial em saúde (Rosa e Labate, 2005). 


\subsubsection{ATENÇÃO PRIMÁRIA NO BRASIL: UM RECORTE PARA O PROGRAMA SAÚDE DA FAMÍLIA}

\subsubsection{HISTÓRICO DO PSF}

Em 1991 houve, no Brasil, a implantação do Programa de Agentes Comunitários de Saúde (PACS) que tinha como alvo contribuir para a redução das mortalidades infantil e materna, principalmente nas regiões Norte e Nordeste do Brasil (Rosa e Labate, 2005).

A partir da experiência acumulada com o PACS, o Ministério da Saúde percebe a importância dos agentes comunitários nos serviços de APS e começa a focalizar a família como unidade de ação programática de saúde, introduzindo a noção de cobertura por família (Rosa e Labate, 2005; Jardim, 2007).

Em 1994 o PACS amplia suas ações pela incorporação de médicos, enfermeiros e auxiliares de enfermagem que junto com os Agentes Comunitários de Saúde (ACS) instituem as primeiras equipes de saúde da família que deram origem ao PSF.

$\mathrm{Na}$ época de sua criação o Brasil contava com 29.000 ACS e as primeiras 55 cidades que implantaram o PSF colocaram em ação 328 equipes de saúde da família ${ }^{7}$

\footnotetext{
${ }^{7}$ Exposição comemorativa PSF [citado em 02/02/2006]

Disponível em: $\underline{\text { http://dtr2001.saude.gov.br/bvs/exposicoes/psf/linhat.html }}$
} 
Considerando a transformação do PSF em uma estratégia de abrangência nacional que demonstra necessidade de adequação de suas normas, em virtude da experiência acumulada nos diversos estados e municípios brasileiros no ano de 2006 o MS adota a Política Nacional de Atenção Básica ${ }^{8}$ (PNAB) (Brasil, 2006a).

A PNAB eleva o PSF da condição de programa a estratégia de reorganização do modelo de atenção à saúde. Nessa direção, Rosa e Labate (2005; p.1030) afirmam que:

"Embora rotulado como programa, o PSF, por suas especificidades, foge à concepção usual dos demais programas concebidos pelo Ministério da Saúde, já que não é uma intervenção vertical e paralela às atividades dos serviços de saúde. Pelo contrário, caracteriza-se como estratégia que possibilita a integração e promove a organização das atividades em um território definido com o propósito de enfrentar e resolver os problemas identificados".

De acordo com a PNAB (Brasil, 2006a) a Atenção Básica caracterizase por um conjunto de ações de saúde, no âmbito individual e coletivo, que abrange a promoção e a proteção da saúde, a prevenção de agravos, o diagnóstico, o tratamento, a reabilitação e a manutenção da saúde (Brasil, 2006a).

\footnotetext{
${ }^{8}$ Atenção Básica no Brasil é utilizado como um sinônimo de APS.
} 
É desenvolvida por meio de práticas gerenciais e sanitárias democráticas e participativas, sob forma de trabalho em equipe, dirigidas a populações de territórios bem delimitados, pelas quais assume a responsabilidade sanitária, considerando a dinamicidade existente no território em que vivem essas populações (Brasil, 2006a).

Utiliza tecnologias de elevada complexidade e baixa densidade, que devem resolver os problemas de saúde de maior freqüência e relevância em seu território.É o contato preferencial dos usuários com os sistemas de saúde.

Orienta-se pelos princípios da universalidade, da acessibilidade e da coordenação do cuidado, do vínculo e continuidade, da integralidade, da responsabilização, da humanização, da equidade e da participação social.

A Atenção Básica considera o sujeito em sua singularidade, na complexidade, na integralidade e na inserção sociocultural e busca a promoção de sua saúde, a prevenção e tratamento de doenças e a redução de danos ou de sofrimentos que possam comprometer suas possibilidades de viver de modo saudável (Brasil, 2006a).

\subsubsection{O PROGRAMA SAÚDE DA FAMILIA}

O PSF tem como objetivo assegurar assistência integral à população por meio da substituição do modelo tradicional, centrado no hospital e na cura de enfermidades, por uma atenção baseada na compreensão ampliada 
do processo saúde-doença, focada na família em seus ambientes físico e social (Brasil, 2001).

Sua estrutura edifica-se a partir da Unidade de Saúde da Família (USF), sendo esta uma unidade pública de saúde, com equipe multiprofissional, que assume responsabilidade por determinada população, a ela vinculada, e promove ações de saúde, prevenção, tratamento e reabilitação de agravos (Brasil, 2001).

A equipe mínima recomendada para a PSF é composta por um médico generalista, um enfermeiro, um a dois auxiliares de enfermagem, e de cinco a seis ACS, procurando manter a relação de um agente para a média de 160 famílias (Brasil, 2001).

De acordo com o MS (Brasil, 2001) cabe às equipes de saúde da família:

- Conhecer a realidade das famílias pelas quais é responsável por meio de seu cadastramento e do diagnóstico de suas características sociais, demográficas e epidemiológicas.

- Identificar problemas de saúde prevalentes e situações de risco aos quais a população está exposta.

- Elaborar, com participação da comunidade, um plano de ação local para enfrentamento dos determinantes do processo saúde-doença.

- Prestar assistência integral, respondendo de forma contínua e racionalizada à demanda, organizada ou espontânea, na USF, 
na comunidade, no domicílio e no acompanhamento ao atendimento dos serviços de referência ambulatorial.

- Desenvolver ações educativas e intersetoriais para o enfrentamento dos problemas de saúde identificados.

É importante salientar que, o legado de ser uma estratégia de atenção à saúde e, ao mesmo tempo, eixo para reorientação do modelo de assistência, imprime características singulares na operação e no modo de trabalhar dos diversos profissionais que compõe as equipes de saúde da família.

Os conceitos de: atenção territorial, trabalho em equipe multiprofissional, atenção familiar, priorização da promoção da saúde e prevenção de doenças, oferta do serviço em domicílio e atuação do ACS destacam-se como pontos fundamentais no modelo de operação proposto pelo PSF.

Embora muitos desses conceitos não tenham sido inaugurados e também não se restrinjam ao PSF, é por meio deste programa que eles serão difundidos com abrangência sem precedentes na história da APS brasileira (Conill, 2008).

Os desdobramentos e as implicações desse modo de funcionar têm sido estudados, desde a implantação do PSF, por diversos autores, tais como: Aleixo, 2002; Alves, 2005; Rosa e Labate, 2005; Magalhães e Senna, 2006; Quaggio, 2007; Lancman et al, 2006; Sznelwar e Issy, 2006; Silva, 2006. 
Sznelwar e Issy (2006) chamam a atenção para o fato de que o modelo de operação do PSF, além de alterar o funcionamento das equipes de saúde da família, influencia também: as relações entre as equipes do programa com outros profissionais ligados direta ou indiretamente à rede de saúde; a relação das equipes com os usuários; e com outros agentes públicos e privados que exerçam algum papel adicional ao sistema.

Alguns autores (Cavalcante et al, 2006; Magalhães e Senna, 2006; Bousquat et al, 2006; Conill,2008) ressaltam a diferença existente, entre o funcionamento das experiências do PSF de um município para outro, e até dentro de um mesmo município, o que é decorrente, dentre outros fatores, do PSF ainda estar em processo de consolidação, das características do local de sua implantação e da sua forma de gestão.

As considerações feitas até aqui se referem as características abrangentes do PSF. A partir deste ponto, serão apresentadas as peculiaridades da implantação e funcionamento do PSF na cidade de São Paulo, por ser este o campo no qual se realiza este estudo.

\subsubsection{O PSF NA CIDADE DE SÃO PAULO}

Segundo Elias et al. (2005), no momento histórico da criação e expansão do PSF no Brasil (1994-1996), a gestão da saúde no Município de São Paulo se afastava dos princípios do SUS pela implantação do Plano de Assistência em Saúde (PAS). Essa conjuntura provocou a nãomunicipalização da saúde na cidade de São Paulo no período de 1994 a 2000. 
Tal cenário acarretou uma necessidade de implantar o PSF na cidade de São Paulo por meio de um convênio entre o MS, a Secretaria Estadual da Saúde (SES) e duas entidades de caráter filantrópico: a Casa de Saúde Santa Marcelina e a Fundação Zerbini, que implementaram o Programa denominado Qualidade Integral em Saúde (QUALIS) nas regiões leste e sudeste de São Paulo (Capistrano Filho, 1999; Santos, 2001).

O Programa QUALIS diferenciou-se do programa nacional de saúde da família não somente em sua forma de gestão, que se deu com o estabelecimento de convênios com organizações sociais no âmbito estadual, mas, também, na incorporação de outros recursos assistenciais de apoio às equipes de saúde da família, tais como saúde bucal, saúde mental e ambulatórios de especialidades (Capozzolo, 2003; Goldbaum et al. 2005).

Com a municipalização da saúde na cidade de São Paulo, ocorrida entre os anos de 2001 a 2004, as unidades do programa QUALIS foram incorporadas à rede municipal como Unidades de Saúde da Família. No entanto, os convênios com organizações privadas não se dissolveram, como ratifica Bousquat (2006):

"Para a operacionalização do PSF, a SMS utilizou-se, como mecanismo para a contratação dos profissionais, da modalidade convênio com instituições privadas, as denominadas organizações parceiras. Essa opção merece ser destacada, pois de certa forma representava a continuidade e a expansão da 
experiência de parcerias iniciada com o QUALIS" (Bousquat et al, 2006, p. 1937).

É importante salientar que, apesar de o PSF, na cidade de São Paulo, após a municipalização da saúde, ter se expandido, ainda apresenta uma baixa cobertura. Segundo dados de uma pesquisa realizada em 2006 (Bousquat et al) dentre os 96 distritos administrativos da cidade, $50 \%$ apresentam cobertura residual (abaixo de 10\%). Somente em três deles (Jardim Ângela, Jaguará e Pari) a cobertura atinge mais de $70 \%$ da população e em apenas um (Vila Curuçá) 100\% da população está coberta pelo PSF. 


\subsection{ARTICULANDO DOIS UNIVERSOS: A INCLUSÃO DA EQUIPE DE ATENÇÃO À SAÚDE DA PESSOA COM DEFICIÊNCIA NO PSF DA CIDADE DE SÃO PAULO.}

A EASPPD tem uma dupla inserção no cenário das políticas públicas de saúde, por um lado, via PSF, e, por outro, via políticas de atenção à saúde da pessoa com deficiência.

No item 1.2.3c deste capítulo, foram descritas as singularidades, na implantação do PSF, que possibilitaram a criação dos serviços de apoio às equipes de saúde da família, dentre os quais se destaca a EASPPD.

Por conseguinte, aqui serão apresentados, através da figura1, os principais eventos ocorridos no percurso das políticas públicas de atenção à pessoa com deficiência na cidade de São Paulo, nos últimos anos, com a finalidade de tecer um panorama que favoreça as análises do serviço da EASPPD também sob essa perspectiva.

\footnotetext{
-

I $1 \quad 1$

1985 19921994

20002001

Figura 1. Linha do tempo - Percurso das políticas públicas de atenção à pessoa com deficiência no município de São Paulo. (Elaborado pelo autor com base em: Oliver (1998), Almeida (2000) e Ho e Oliver (2005).)

- 1985 - Implantação dos primeiros serviços de reabilitação em serviços públicos de saúde inclusive na APS.
} 
- 1992 - Proposta de organização da atenção à população com deficiência no município de São Paulo, protagonizada por profissionais ligados à prefeitura e à SES, bem como por representantes dos movimentos das pessoas com deficiência.

- 1994 a 2000 - Interrupção das proposições do grupo constituído em 1992 por causa do cenário político do município de São Paulo.

- 2000 - Implantação da Equipe de Atenção à Saúde da Pessoa Portadora de Deficiência junto com as equipes do PSF das zonas leste e sudeste da cidade.

- 2001 - Municipalização da saúde em São Paulo e retomada das propostas de organização da atenção à saúde da pessoa com deficiência.

\subsubsection{A EQUIPE DE ATENÇÃO À SAÚDE DA PESSOA PORTADORA DE DEFICIÊNCIA (EASPPD): HISTÓRICO E FUNDAMENTOS.}

A EASPPD foi implantada em 2000, como um recurso assistencial de apoio às equipes nucleares do PSF/QUALIS das regiões leste e sudeste da cidade de São Paulo.

O grande desafio lançado diante deste serviço foi aliar a reabilitação, cuja tradição histórica remetia ao modelo de assistência prestado nos grandes centros de reabilitação, a uma modalidade singular de atenção à pessoa com deficiência calcada nos cuidados primários de saúde. 
Para tanto, foi elaborado um projeto denominado: Implantação do Programa de Atenção à Saúde da Pessoa Portadora de Deficiência no Programa Saúde da Família - QUALIS (Rocha e Kretzer, 2000). Esse projeto preconizou que a $\mathrm{RBC}$ seria a estratégia para inserção da equipe de reabilitação no PSF/QUALIS (Rocha e Kretzer, 2000)

Para operar suas ações, o projeto de implantação da EASPPD preconizou um modelo interdisciplinar de atuação contando com Fisioterapeutas, Fonoaudiólogos e Terapeutas Ocupacionais, divididos em duplas responsáveis por oito a dez equipes de saúde da família (Rocha et al, 2002)

Também foi previsto, pelo projeto de implantação da EASPPD, que as atividades desenvolvidas pelos profissionais de reabilitação deveriam ser integradas às ações programáticas do PSF (Ex.: campanhas de vacinação, visitas domiciliares, etc.), às demandas da rede de saúde local e, também, da rede intersetorial (atuação em escolas, em centros comunitários, etc.).

Caberia à EASPPD promover a capacitação continuada das equipes de saúde da família sobre a abordagem dos problemas relativos à população com deficiência e incapacidades buscando possibilidades de intervenção disponíveis no território de abrangência da Unidade de Saúde da Família.

Vale ressaltar que o projeto de implantação da EASPPD previa sua expansão para outras regiões da cidade de São Paulo, porém, com a municipalização das unidades QUALIS, apenas um ano após a implantação da EASPPD a experiência ficou restrita aos locais onde foi implantada. 


\section{APORTE TEÓRICO}

Este capítulo visa oferecer ao leitor as bases conceituais utilizadas na construção deste estudo. Para tanto, será apresentada uma introdução ao campo de estudo da produção de serviços abordando os seguintes aspectos desse quadro teórico:

- DEFINIÇÃO DE SERVIÇO

- CONCEITO DO SERVIÇO

- O VALOR DO SERVIÇO

- CARACTERÍSticas fUndamentais da operação DE SERVIÇOS

- CLASSIFICAÇÃo dE SERVIÇOS

- SERVIÇOS PROFISSIONAIS EM DETALHES

- SERVIÇO PÚBLICO: DEFINIÇÃO E CARACTERÍSTICAS 


\subsection{INTRODUÇÃO AO CAMPO DE ESTUDO DA PRODUÇÃO NO SETOR DE SERVIÇOS}

\subsubsection{DEFINIÇÃO DE SERVIÇO}

Na literatura de gestão de serviços, as definições de serviço não são únicas e têm avançado historicamente. Inicialmente, a definição de serviço foi construída por comparação à produção de bens e/ou por contraposição a esta. Desse período encontram-se definições como: bens são tangíveis e serviços são intangíveis ${ }^{9}$ (Bowen e Ford, 2002).

No entanto, esses primeiros esforços para definir o que é serviço não conseguiram dar contorno a uma gama de atividades que se encontram fora da esfera da produção de bens materiais e que abrangem desde 0 oferecimento de energia elétrica até 0 atendimento realizado por um profissional de saúde (Bowen e Ford, 2002).

Neste sentido, outras definições surgiram tentando abarcar a amplitude de atividades que se enquadram na categoria de serviços. Um exemplo dessas formulações encontra-se na seguinte definição: serviço é um ato ou performance oferecida de uma parte para outra, e mesmo que o processo de produção esteja atado a um bem material, a performance é essencialmente intangível e não resulta em propriedade de nenhum dos fatores de produção (Bowen e Ford, 2002; Lovelock, 2000).

\footnotetext{
${ }^{9}$ Tangível: Adj 2 gén. Que se pode tanger, tocar ou apalpar. Sensível, palpável. Disponível em: http://www.priberam.pt/dlpo/definir_resultados.aspx acessado em: 14.04.2008.

No tópico 2.2.1, o atributo da intangibilidade na produção de serviços será apresentado em detalhe.
} 
Essas definições de serviço ainda são derivadas da produção de bens e apresentam como conseqüência uma ênfase nos recursos mobilizados para produção de determinados resultados. Zarifian (2001a), ao analisar essas definições, aponta fragilidades, como o fato de que o serviço não pode ser reduzido a uma performance, nem mesmo a uma transformação física ou mental; pois o serviço também produz um valor.

Nesta direção, Zarifian (2001a) afirma que o serviço é a transformação nas condições de atividade do usuário. Sendo assim, numa consulta médica o serviço prestado não é a consulta em si, mas a saúde recobrada.

A introdução do valor do serviço, trazida pela definição de Zarifian (2001a), estabelece duas perspectivas para avaliação do serviço, uma que parte dos resultados e outra dos recursos.

Do ponto de vista dos resultados, o serviço é uma transformação nas condições de atividade do destinatário (consumidor, cliente, usuário, etc.), cujos resultados são considerados válidos e positivos por este último ou pela coletividade.

A partir dos recursos, a avaliação do serviço pode ser vista como a organização e mobilização mais eficiente possível de recursos visando interpretar, compreender e produzir a transformação antes mencionada.

Note-se que a definição de serviço por meio dos resultados guia a definição por meio dos recursos, já que é a partir dos resultados produzidos que a eficiência no uso dos recursos adquire sentido. 
Partindo dessa definição, é difícil pensar no serviço entregue (resultado) dissociado da sua produção (recursos). No que diz respeito a esta pesquisa, é interessante apontar ainda que, enquanto na literatura de gestão de serviços há grande preocupação com a mobilização de recursos (menor quantidade de recursos para obter melhores resultados), na literatura de planejamento de serviços públicos de saúde parece haver uma ênfase na descrição dos resultados dos serviços.

Um problema que pode decorrer dessa ênfase dada aos resultados esperados é a criação de serviços com recursos sub-dimensionados ou superestimados, o que dificultaria, inclusive, a avaliação desses serviços.

Esse quadro pode ser verificado tanto na literatura acadêmica (Merhy, 2003, 2004, 2007; Campos, 1998) como em documentos oficiais que normatizam o funcionamento de serviços de saúde (Brasil 2001, 2006). Para ilustrar essa situação segue um trecho de um dos documentos que normatizam o funcionamento do PSF (Brasil, 2001), no qual os objetivos do serviço são apresentados somente a partir dos resultados esperados:

O objetivo do PSF é a reorganização da prática assistencial em novas bases e critérios, em substituição ao modelo tradicional de assistência, orientado para cura de doenças e realizado principalmente no hospital, A atenção está centrada na família, entendida e percebida no seu ambiente físico e social, o que vem possibilitando às equipes de saúde da família uma compreensão ampliada do conceito 
saúde/doença e das intervenções que vão além das práticas curativas (Brasil, 2001 p.5).

Por outro lado para planejar, e gerenciar, recursos que permitam a obtenção de resultados esperados no setor de serviços é necessário conhecer as características desse modo de produção.

Neste sentido, a seguir, serão apresentadas as características fundamentais da operação de serviços que fundamentaram a análise do serviço da EASPPD então desenvolvida.

\subsubsection{O CONCEITO DO SERVIÇO}

O conceito do serviço é um conjunto de princípios que define quais os valores serão entregues ao usuário e, ao mesmo tempo, explicita quais serão os recursos mobilizados pelo trabalhador para entregar o serviço proposto (Kingman - Brundage, 1993).

Nesta direção, Silva (2006, p.27) aponta que:

Do lado da empresa, ele significa a forma como ela projeta os seus serviços e oferece-os a seus usuários. Do ponto de vista do cliente, o conceito do serviço representa a maneira pela qual ele entende e valoriza aquilo que a organização está lhe oferecendo.

A aplicação do conceito de serviços na gestão de empresas privadas é bastante difundida e serve para definir os elementos que nortearão o 
desenvolvimento do pacote de serviços e também a estratégia de operação. Entretanto, ainda há pouca discussão sobre a aplicabilidade dessa abordagem no estudo de organizações públicas e dos serviços prestados a seus usuários (Quaggio et al, 2005).

Os elementos-chave que embasam a construção do conceito de um serviço são (Johnston e Clark, 2002):

- Experiência do serviço: Experiência oriunda do processo de serviço percebida pelo cliente que ocorre no momento da entrega do serviço.

- Resultado do serviço: Aquilo que o cliente espera receber.

- Operação do serviço: O modo pelo qual o serviço é entregue identificando os recursos e processos.

- Valor: Pode ser avaliado a partir dos recursos mobilizados e/ou dos resultados produzidos.

No que diz respeito às analises propostas para este estudo, os seguintes elementos acima serão explorados: resultado do serviço, a operação e o valor do serviço.

Para analisar a operação do serviço, será utilizada a estrutura inspirada em referenciais que destacam as seguintes áreas de projeto em serviço (Voss, 2007):

- Ambiente físico (cenário): Lugar em que a experiência do serviço é vivenciada (Ex.: Hospital, Unidade Básica, domicílio). 
- Trabalhadores de linha de frente (atores): Profissionais responsáveis pela entrega do serviço que vão interagir com o usuário.

- Processo de operação do serviço (roteiro): É o roteiro de entrega do serviço. A série de ações ou eventos organizados para entregar o serviço.

- Outros espectadores no encontro de serviço (platéia): Pessoas que assistem a entrega do serviço (trabalhadores de outra linha hierárquica, acompanhantes de usuários, etc.).

- Interação com a retaguarda (back stage): Interligação prevista entre trabalhadores da linha de frente e demais níveis hierárquicos da organização.

\subsubsection{AVALIAÇÃO DO VALOR DO SERVIÇO}

No que diz respeito à avaliação do valor do serviço, será utilizada a abordagem proposta por Zarifian (2001a) que, como explicitado no tópico anterior, pode assumir a perspectiva dos recursos ou dos resultados.

Para a avaliação a partir dos resultados, quatro tipos de abordagens complementares são possíveis:

\section{- Avaliação de utilidade:}

Essa é a avaliação mais utilizada, pois permite identificar resultados úteis à atividade do destinatário, ou, ainda, como o serviço muda 
positivamente as condições da atividade do usuário. Se o resultado útil não for produzido, o serviço não terá sido realmente prestado.

\section{- Avaliação de justiça:}

A avaliação de justiça é expressa em termos de direitos, nesse caso, todo cidadão pode usufruir esse serviço, independentemente de sua origem social ou sua renda.

Nesse caso, para o serviço transformar as condições de um indivíduo é necessário além do acesso ao serviço, a existência de condições para que o usuário se aproprie dele. Desse modo, o valor, na abordagem de justiça, leva em conta as necessidades particulares dos usuários, assim como, a disponibilidade de meios de acesso diferenciados que favoreçam um acesso universal ao serviço.

Quanto maior a consciência da operação do serviço, sobre as necessidades particulares de seus usuários, mais resultados úteis podem ser obtidos, proporcionando, assim, a mudança mais efetiva nas condições de atividade do usuário.

\section{- Avaliação de solidariedade:}

Surge cada vez que há necessidade de ajuda mútua (problemas relativos ao coletivo). Nesses casos, Zarifian (2001a, p. 19) afirma que: “(..) prestar serviço é agregar uma decisão de solidariedade a um ato ou a uma produção concreta, endereçada ao outro. É exprimir a interdependência dos indivíduos e de suas atividades". 


\section{- Avaliação estética:}

Avaliação de beleza e de ética. Um misto de belo e bom que congrega formas subjetivas de apreço. (Ex.: Exibição de um filme ou exposição de uma obra de arte que modificam o outro).

Realizada a avaliação do valor a partir dos resultados, pode ser feita a avaliação do valor dos serviços na perspectiva dos recursos. Para Zarifian (2001b), a eficiência (relação entre resultados e recursos) deve ser avaliada sempre em função dos resultados propostos.

Assim sendo, a transformação das condições de atividade do destinatário (resultado do serviço) deve ser produzida com eficiência no uso dos recursos da organização.

\subsubsection{CARACTERÍSTICAS FUNDAMENTAIS DA OPERAÇÃO DE SERVIÇOS}

A intangibilidade, Produção Simultânea ao Consumo ou Inseparabilidade, Perecibilidade e Heterogenidade são as principais características que diferenciam a produção de serviço da produção de bens materiais (Bowen e Ford, 202)

Seguem as definições de cada um desses atributos da produção de serviço com breve apresentação das suas implicações na operação destes. 
- INTANGIBILIDADE

Alguns autores apontam a intangibilidade como atributo principal na caracterização do serviço, visto que a sua essência está na performance oferecida de uma parte (prestador de serviço) para outra (destinatário do serviço) ( Bowen e Ford, 2002; Lovelock, 2000).

Sendo, a performance, essencialmente intangível, ela pode ser experimentada por seus atores, mas raramente poderá ser vista, sentida ou tocada de maneira análoga a um bem concreto (Quaggio, 2007).

A intangibilidade, dessa maneira, relaciona-se com a experiência gerada na produção do serviço e, portanto, será guardada na mente e não nas mãos do seu destinatário (Bowen e Ford, 2002). Assistir a uma peça de teatro é um exemplo da intangibilidade do serviço, já que, ao terminar a apresentação, não se leva o espetáculo para casa, mas os espectadores se tornam portadores das sensações, emoções e idéias que foram apresentadas como produto do serviço.

Os serviços de saúde, como todos os outros tipos de serviço, podem ser permeados em maior ou menor intensidade pela intangibilidade. Por exemplo, uma fratura reduzida pode ser observada por meio de instrumentos de diagnóstico por imagem. Por outro lado, em se tratando de um atendimento clínico de psiquiatria não há a possibilidade de verificação direta dos resultados.

Nos serviços de reabilitação a depender dos objetivos a serem atingidos verifica-se, também, maior ou menor grau de intangibilidade. Se o 
foco do serviço é sobre o dano em estrutura do corpo (Por exemplo, diminuir uma deformidade) este resultado é mais tangível do que aquele esperado de serviços que visam aumentar a participação social.

Destaca-se, então, que a intangibilidade é um ponto crítico na operação de serviços, na medida em que dificulta o conhecimento, a avaliação e a decisão do destinatário do serviço de forma preestabelecida.

Voltando aos exemplos anteriores, um indivíduo só pode avaliar uma peça de teatro após tê-la assistido, e um usuário só pode avaliar os benefícios de um atendimento em saúde mental após tê-lo recebido.

Nesse sentido, Quaggio (2007) assinala que a utilização freqüente de um determinado serviço leva ao acúmulo de um conjunto de informações derivadas de sucessivas experiências que se constituem na representação de expectativas e avaliações, em relação ao serviço original, por parte de usuários e prestadores de serviço.

Nos casos de implantação de novos serviços (inovação), ou mudanças em serviços já estabelecidos, essas alterações, que passam muitas vezes pela modificação do conceito do serviço e, por conseqüência, no sistema de operações, vão influenciar (Quaggio, 2007):

- A percepção do destinatário do serviço a respeito dos resultados esperados, a qual pode remeter suas expectativas a experiências pregressas.

- O prestador de serviço (trabalhador da linha de frente) que poderá recorrer às suas experiências anteriores para entregar o serviço, 
mesmo que estas estejam desalinhadas com as propostas do projeto do novo serviço.

- INSEPARABILIDADE:

A essas questões da expectativa e avaliação do serviço, ligadas à experiência, também está relacionado o atributo da inseparabilidade. Enquanto produtos são produzidos, entregues e posteriormente consumidos, no caso dos serviços, a produção dá-se de forma concomitante ao seu consumo (Quaggio, 2007; Bowen e Ford, 2002).

A inseparabilidade, na produção de serviços, pode ser ilustrada nos serviços de transporte urbano, consultas médicas ou em um corte de cabelo. Em todos esses casos, a presença do destinatário do serviço é indispensável para que a produção do serviço ocorra. O consumo do serviço é concomitante a sua entrega, afinal, não se pode estocar consultas médicas ou viagens de metrô, para consumi-los em outra ocasião.

Em serviços de saúde Merhy (2003 p.3), aponta a presença do atributo da inseparabilidade: “(...) trabalho em saúde é sempre relacional, porque é dependente de Trabalho Vivo em ato, isto é, o trabalho no momento em que este está produzindo (...)".

É importante sublinhar que essa característica da operação de serviço desloca parte da responsabilidade do resultado obtido para o destinatário, que passa, em muitos casos, a ser um co-realizador do serviço. 
Diante desse fato, cabe às organizações de serviço preparar os seus usuários para conhecer qual o seu papel no processo de produção. Tome-se como exemplo uma rede de fast food, que prescinde do serviço de garçons. Nesse caso, o cliente deve estar preparado para fazer seu próprio pedido e servir-se ou, então, corre-se o risco de atrasar a operação do serviço para atender a demandas não originárias desse tipo de restaurante.

No caso dos serviços de saúde, os usuários também precisam compreender as atribuições dos serviços que procuram, para alinhar suas expectativas com aquilo que o serviço oferece.

Desse modo, importa que usuários de uma unidade básica de saúde saibam que naquele espaço não se realizam procedimentos de alta complexidade, do mesmo modo que o pronto-socorro de um hospital não é local para realizar uma consulta pré - natal.

Para os trabalhadores de linha de frente, 0 atributo da inseparabilidade abre espaço para que se modifique a operação do serviço seja para que melhores resultados sejam obtidos, segundo seu julgamento, ou para contemplar preferências na execução de suas tarefas.

- PERECIBILIDADE:

Em conseqüência do atributo da inseparabilidade, os serviços são perecíveis, isso significa que não podem ser estocados ou salvos para uso posterior, revendidos ou devolvidos à organização (Quaggio, 2007). 
Um assento em uma aeronave, se não ocupado em determinado trecho, não pode ser armazenado para uso posterior, ele está perdido para sempre, assim como um quarto de hotel que não foi utilizado em um pernoite ou uma consulta médica não realizada porque o paciente não compareceu.

As implicações da perecibilidade dos serviços relacionam-se com a flutuação da demanda. Nesse sentido, no momento de projetar o serviço, deve ser dada especial atenção para a capacidade do serviço, o qual deve ser dimensionado a partir de um estudo da demanda para não sobrecarregar o sistema de produção.

- HETEROGENEIDADE:

Outro aspecto que caracteriza os serviços e a sua produção é a heterogeneidade, visto que a qualidade e, até mesmo, a essência do serviço têm alto potencial de variabilidade (Quaggio, 2007).

A principal fonte de heterogeneidade é a flutuação no desempenho dos trabalhadores, no entanto, não é seu único determinante. Se o destinatário é um co-produtor do serviço, ele também atuará interferindo no processo de produção de maneira singular (Bowen e Ford, 2002).

Nesse contexto, Merhy e Franco (2003) destacam que em serviços de saúde a heterogeneidade está relacionada, principalmente, ao trabalhador de linha de frente como ilustrado no trecho que segue:

Os estudos que têm se dedicado a observar e analisar a forma como se produz saúde, indica que esse é um 
lugar onde os sujeitos trabalhadores, individuais e coletivos, agem de forma interessada, isto é, de acordo com projetos próprios, sejam estes de uma dada corporação, ou mesmo da pessoa que ocupa um certo espaço de trabalho (Merhy e Franco, 2003 p.2)

Vale ressaltar que na literatura de gestão de serviços públicos em saúde a participação do usuário na composição do resultado do serviço é pouco explorada.

\subsubsection{CLASSIFICAÇÃO DE SERVIÇOS}

A categoria serviço engloba uma gama extensa de atividades, portanto alguns sistemas para classificação de serviços foram elaborados. Devido ao escopo deste trabalho, será apresentada de maneira concisa, uma destas classificações, proposta por Silvestro (1999), que divide os serviços nas seguintes categorias:

\section{- Serviços em massa:}

São aqueles que envolvem pouco tempo de contato entre clientes e o profissional de linha de frente e padronização do serviço. Aqui se enquadram, por exemplo, os serviços de distribuição de energia elétrica e telefonia.

\section{- Lojas de serviços:}

As lojas de serviço são uma categoria intermediária. Apresentam serviços padronizados, porém com algum espaço para customização e 
um tempo médio de contato entre clientes e trabalhadores de linha de frente. Fazem parte dessa categoria serviços bancários, educacionais e hospitalares.

\section{- Serviços profissionais:}

Esses serviços se caracterizam pela elevada autonomia que trabalhadores de linha de frente possuem para entregar serviços altamente customizados. Também se verifica, nesses tipos de serviço a necessidade de maior contato entre os usuários e prestadores de serviço. Fazem parte dessa categoria, serviços de saúde ambulatoriais e consultorias.

O serviço da EASPPD se enquadra nas características dos serviços profissionais. Portanto a seguir será realizada uma apresentação mais detalhada de sua tipologia.

\subsubsection{SERVIÇOS PROFISSIONAIS EM DETALHES}

"Serviços profissionais são aqueles em que o destinatário do serviço busca no fornecedor uma capacitação de que não dispõe" (Giannesi e Correa, 1994 apud Quaggio, 2007).

Nessa perspectiva, os serviços profissionais são aqueles realizados por uma pessoa, ou organização, que possui conhecimento especializado nas áreas social e/ou acadêmica, e pode ser utilizado para atender às mais diversas necessidades de outras pessoas ou organizações (Quaggio, 2007). 
Desse modo, a realização dos serviços profissionais requer de seus trabalhadores, qualificação e habilidades diferenciadas, além do desenvolvimento de competências específicas o que torna o conhecimento o maior produto dos serviços profissionais.

O elevado tempo de contato entre prestadores e destinatários do serviço é necessário em serviços profissionais para que haja o atendimento de necessidades específicas de cada cliente de forma única (Quaggio, 2007).

No que concerne ao processo de produção, os serviços profissionais são marcados pela forte presença das quatro características da produção de serviços: intangibilidade, inseparabilidade, perecibilidade e heterogeneidade.

Isso acontece porque, nesse tipo de serviço, devido a customização a definição dos resultados é tênue, a autonomia dos profissionais que entregam o serviço é alta e a avaliação do destinatário do serviço, a despeito de sua participação ativa no processo de produção, fica comprometida (Quaggio, 2007).

Diante do exposto, devido à baixa especificidade das tarefas e à ampla autonomia dos profissionais, o conceito de serviço é o único elemento que permanece constante entre a execução de um serviço para outro.

A gestão dos serviços profissionais deve atuar no sentido de garantir a fluência do trabalho entre os diversos grupos de profissionais e o suporte dos sistemas técnicos de apoio. 
Mais detalhadamente, nesta direção, caberá aos gestores, segundo Quaggio (2007), garantir a melhoria no fluxo de informações entre profissionais, organizações e destinatários do serviço, acumular experiências anteriores para subsidiar trabalhos futuros, fomentar o processo de produção por meio da sua sistematização, ou da redução de burocracias.

Vale ressaltar ainda que, como os serviços profissionais estão centrados nos trabalhadores de linha de frente, a gestão de recursos humanos é fator crucial nesses serviços.

Sendo assim, cabe aos gestores, segundo (Quaggio, 2007), a tarefa de recrutar profissionais preparados para responder às demandas de determinado serviço; oferecer treinamento técnico e supervisão aos trabalhadores, de forma a facilitar a convergência entre o trabalho realizado e o trabalho esperado por esses profissionais.

O serviço da EASPPD é um serviço profissional que, além de carregar as características explicitadas até o momento, ainda apresenta influências de outro tipo de produção de serviços que é o serviço público. A seguir, suas definições e características serão apresentadas. 


\subsubsection{SERVIÇO PÚBLICO: DEFINIÇÃO E CARACTERÍSTICAS}

Silva (2007) aponta que a definição de serviço público deve necessariamente vir acompanhada da compreensão mais abrangente do papel do Estado no desenvolvimento de ações de proteção à população.

Nesse sentido, destaca-se como característica marcante do Estado, na atualidade, a constituição de um conjunto de indivíduos que, juntamente com a disponibilização de recursos materiais, atua em benefício da população, sob as ordens de um governo. A essa expressão do Estado, via ações concretizadas por poder que comanda e controla ações voltadas ao público, é que se denomina de serviço público (Derani, 2002).

Esses serviços são caracterizados pela intensa regulação dos processos de atendimento e pelo acesso eqüitativo via direitos legais (Gummesson, 1994; Quaggio, 2007).

Quanto aos serviços públicos de saúde brasileiros, é importante ressaltar que estes são oferecidos dentro da esfera do SUS calcados nos princípios da Eqüidade, Integralidade e Universalidade, mediante a premissa de que a "Saúde é um direito de todos e um dever do estado" (Brasil, 1990).

No que diz respeito à produção de serviços públicos de saúde no Brasil, Silva (2007) chama a atenção para o fato de que a distância entre linha de frente e a retaguarda dos serviços ${ }^{10}$ é acentuada, fazendo com que problemas identificados no processo de prestação do serviço não sejam

\footnotetext{
${ }^{10}$ A retaguarda de serviços públicos de saúde são os órgãos decisores ou regulamentadores das políticas e práticas de saúde que se encontram nas esferas municipais, estaduais e federal.
} 
conhecidos ou entendidos por aqueles que poderiam resolvê-los, ao mesmo tempo em que os mais próximos da linha de frente não entendem a visão praticada pela retaguarda. Essa falta de compreensão mútua faz crescer as dificuldades para correção do projeto ou implantação de novas formas de executar o serviço.

Nessa direção, Campos (1998), ressalta a necessidade de se instituir um novo modelo de gestão do sistema de saúde que possibilite, por um lado, o alcance dos objetivos primários dos serviços (produzir saúde), e, por outro, assegure a realização profissional de seus trabalhadores com dispositivos que proporcionem maior horizontalização na gestão desses serviços. 


\section{OBJETIVO}

Conhecer e caracterizar o processo de trabalho do serviço de uma EASPPD da cidade de São Paulo buscando compreender como seu conceito, apresentado em seu projeto de implantação ${ }^{11}$, é transformado em ação e resulta em um serviço para o usuário

Objetivos específicos:

- Identificar o conceito do serviço da EASPPD buscando desvelar os elementos que constituem a sua estratégia de operação.

- Conhecer, sob o ponto de vista dos trabalhadores, aspectos da organização do trabalho da EASPPD.

\footnotetext{
${ }^{11}$ O projeto de implatação da EASPPD se configurou no documento: Programa de Atenção a Saúde da Pessoa Portadora de Deficiência e Incapacidade no PSF/QUALIS - SP. Zona leste e sudeste do município de São Paulo (Rocha e Kretzer, 2000).
} 


\section{MÉTODO}

Esta pesquisa se localiza no campo da investigação qualitativa e se configura como um estudo de caso do tipo exploratório que, de acordo com a definição de Yin (2003, p. 32), é "uma investigação empírica, que averigua um fenômeno contemporâneo dentro de seu contexto de vida real, especialmente quando os limites entre o fenômeno e o contexto não estão claramente definidos".

Estudos de Caso, tipicamente, combinam várias estratégias de coleta de dados como entrevistas, observações, questionários, análise de registros (prontuários, arquivos, bancos de dados, etc.), e posterior triangulação desses dados, com a finalidade de garantir o rigor do método de pesquisa e validade dos resultados encontrados ( $\square$ os set al 2002).

Nessa direção, para a elaboração do Estudo de Caso Yin (2003) recomenda a adoção dos seguintes princípios:

\section{- Usar múltiplas fontes de evidência:}

O uso de múltiplas fontes de evidência permite investigar vários aspectos em relação ao mesmo fenômeno. As conclusões e descobertas ficam mais convincentes e apuradas, já que, advém de um conjunto de corroborações. Além disso, os possíveis problemas de validade de constructo têm mais chances de serem solucionados, pois os achados, nestas condições, são validados através de várias fontes de evidência. 


\section{- Construção de uma base de dados:}

Embora em Estudos de Caso a separação entre a base de dados e 0 relato não seja comumente encontrada, sugere-se que essa separação aconteça. Essa recomendação é feita para buscar o aumento da confiabilidade do estudo, uma vez que os dados encontrados são armazenados, o que possibilita o acesso de outros investigadores.

Os registros dessa base de dados podem se dar através de: notas, documentos, tabulações e narrativas (interpretações e descrições dos eventos observados, registrados).

\section{- Elaboração de uma cadeia de evidências:}

Construir uma cadeia de evidências consiste em configurar o Estudo de Caso, de tal modo, que se consiga levar o leitor a perceber a apresentação das evidências que legitimam o estudo, desde as questões de pesquisa até as conclusões finais. Salienta, também, que o relato do Estudo de Caso deve sempre buscar assegurar que as evidências apresentadas não sejam maculadas por vieses.

\subsection{DESENHO DA PESQUISA}

Os preceitos do Estudo de Caso apresentados anteriormente serviram de base para a elaboração do desenho desta pesquisa. As fontes de evidências, bem como, a finalidade da utilização de cada uma delas serão apresentadas na tabela 3. 


\begin{tabular}{|c|c|c|}
\hline Fonte & Detalhe & Finalidade \\
\hline $\begin{array}{l}\text { Documento de } \\
\text { implantação da } \\
\text { EASPPD }\end{array}$ & & $\begin{array}{l}\text { Identificação do conceito do } \\
\text { serviço da EASPPD }\end{array}$ \\
\hline $\begin{array}{l}\text { Entrevistas com } \\
\text { profissionais da } \\
\text { EASPPD }\end{array}$ & $\begin{array}{l}\text { Entrevistas semi estruturadas guiadas } \\
\text { por um roteiro (anexo 1). }\end{array}$ & $\begin{array}{l}\text { Conhecer, sob a perspectiva } \\
\text { dos trabalhadores, aspectos da } \\
\text { organização do trabalho da } \\
\text { EASPPD. }\end{array}$ \\
\hline $\begin{array}{l}\text { Questionário } \\
\text { (anexo 2) }\end{array}$ & & $\begin{array}{l}\text { Elaborar um perfil das } \\
\text { características da equipe. }\end{array}$ \\
\hline $\begin{array}{l}\text { Fontes de } \\
\text { informações } \\
\text { secundárias }\end{array}$ & $\begin{array}{l}\text { Documentos do MS que se referem a: } \\
\text { Normatização da atenção à saúde da } \\
\text { pessoa com deficiência } \\
\text { Políticas Públicas de atenção } \\
\text { primária/PSF } \\
\text { Publicações da prefeitura da cidade de } \\
\text { São Paulo referentes ao PSF e a } \\
\text { atenção a pessoa com deficiência no } \\
\text { município. }\end{array}$ & $\begin{array}{l}\text { Conhecer o cenário no qual a } \\
\text { EASPPD estudada está } \\
\text { inserida. } \\
\text { Complementar as análises das } \\
\text { outras fontes de evidência.. }\end{array}$ \\
\hline
\end{tabular}

Tabela 3 - Fontes de dados utilizados no estudo (elaborado pelo autor) 


\subsection{PROCEDIMENTOS}

\subsubsection{PROCESSO DE APROXIMAÇÃO COM O CAMPO DE PESQUISA}

Para viabilizar a realização da coleta de dados em campo foi necessário tecer uma interlocução com diferentes atores relacionados ao serviço estudado.

Desse modo, foram encaminhadas cartas de apresentação, com cópias do projeto de pesquisa anexadas, para a Coordenadoria Regional de Saúde Leste da cidade de São Paulo, bem como, para gestores da Casa de Saúde Santa Marcelina que é a instituição parceira da SMS de São Paulo na gestão do PSF da região na qual se insere o serviço analisado.

O passo seguinte foi a apresentação dessa pesquisa por meio de um resumo do projeto de pesquisa (anexo 3), para a gerente da unidade de saúde que sediou a coleta de dados.

Esse contato, com a gerência da unidade, propiciou o agendamento da apresentação do projeto de pesquisa para os profissionais da EASPPD, por meio de exposição oral, durante uma reunião mensal regular desta equipe ocorrida em abril de 2007. Nessa apresentação também foi informado aos trabalhadores que a participação nessa pesquisa tinha caráter voluntário. 


\subsubsection{O QUESTIONÁRIO DE CARACTERIZAÇÃO DA EASPPD}

A aplicação do questionário foi feita no mesmo dia da apresentação do projeto de pesquisa aos profissionais da EASPPD. Todos os dez integrantes da equipe estudada responderam ao questionário.

Esse instrumento de pesquisa foi elaborado para colher informações que caracterizassem os profissionais da EASPPD focada nos seguintes aspectos:

- Categoria Profissional

- Sexo

- Idade

- Tempo de trabalho na equipe

- Formação para o trabalho no PSF.

A análise dos dados do questionário foi realizada por meio da tabulação dos dados.

\subsubsection{A REALIZAÇÃO DAS ENTREVISTAS}

No que concerne às entrevistas, estas foram do tipo semi estruturadas e contaram com um roteiro (Anexo 1) que serviu de guia para balizar os assuntos a serem abordados pelo pesquisador.

Antes de se iniciarem as entrevistas o roteiro foi apresentado aos sujeitos da pesquisa, para que estes pudessem se aproximar das questões 
abordadas. É importante observar que o entrevistador buscou interferir o mínimo possível no discurso dos entrevistados para não induzir respostas.

A coleta dos depoimentos dos trabalhadores da EASPPD foi realizada no período de maio a setembro de 2007. Nesse período a EASPPD especificada contava com dez integrantes. Destes, sete aceitaram participar do estudo, um, encontrava-se de licença maternidade, e outros dois, não se dispuseram a participar dessa parte da coleta de dados.

Todas as entrevistas foram realizadas no local de trabalho da EASPPD, em períodos previamente agendados com os trabalhadores, sendo gravadas e posteriormente transcritas na íntegra.

\subsubsection{PESQUISA DOCUMENTAL E BIBLIOGRÁFICA}

Segundo Gil (2006) a pesquisa documental e a pesquisa bibliográfica se diferem pela natureza de suas fontes, No entanto, os procedimentos para o desenvolvimento de ambas são os mesmos.

A pesquisa documental tem como fonte documentos de primeira mão que não receberam nenhum tratamento analítico, tais como: documentos institucionais conservados em arquivos, documentos de uso restrito, leis, regulamentos, catálogos, cartilhas, entre outros, enquanto que a pesquisa bibliográfica é desenvolvida com base em material já elaborado como livros e artigos científicos (Gil, 2006).

O procedimento técnico inicial para realização da pesquisa documental foi o levantamento do material empírico (cartilhas, material de 
divulgação, manuais), em arquivos da Casa de Saúde Santa Marcelina ${ }^{12}$ e da SMS que apresentavam em seu conteúdo dados significativos para a construção do estudo de caso que aqui se apresenta.

A pesquisa bibliográfica foi realizada em duas etapas. A primeira visou fundamentar a elaboração do projeto de pesquisa tendo sido realizada entre os meses de agosto e setembro de 2006.

A segunda etapa teve como objetivos:

- Aprofundar a reflexão e discussão a respeito dos eixos fundamentais da contextualização dessa pesquisa (Campo de Atenção à saúde da pessoa com Deficiência, Atenção Primária na modalidade Saúde da Família),

- Elaboração do aporte teórico

- Levantamento de dados para complementar a análise dos dados de outras fontes de evidência.

O levantamento dos dados da pesquisa bibliográfica foi realizado em bases nacionais e internacionais, tais como: Scielo, Emerald, OVID, Lilacs, além de livros, teses e documentos eletrônicos.

\subsubsection{PROCEDIMENTOS DE ANÁLISE DE CONTEÚDO}

Os procedimentos para análise dos dados colhidos para essa pesquisa basearam-se em preceitos de Franco (2004) e seguiram as seguintes etapas:

\footnotetext{
${ }^{12}$ A Casa de Saúde Santa Marcelina é uma instituição parceira da SMS na gestão do PSF e que foi uma das sedes da implantação da EASPPD na cidade de São Paulo
} 
- Pré-análise: Leitura minuciosa do material visando selecionar e organizar os conteúdos encontrados.

- Exploração do material: busca, no texto, de conteúdos que respondessem aos objetivos especificados.

- Tratamento dos resultados: Reordenação dos dados obtidos nas etapas anteriores da análise e interpretação dos resultados.

\subsection{ANÁLISE DOS RESULTADOS E ELABORAÇÃO DO RELATO DO ESTUDO DE CASO DA EASPPD}

Basear-se em proposições teóricas é a forma mais comum para se analisar as evidências de um caso. Isso se deve segundo Yin (2003), ao fato de que os objetivos e o desenho iniciais do estudo, presumivelmente, foram baseados sobre essas proposições, as quais devem refletir um conjunto de questões de pesquisa, revisões da literatura e novos "insights".

Sendo assim, o aporte teórico apresentado no capítulo 2 desta dissertação foi o eixo que direcionou a análise do estudo de caso aqui apresentado, estabelecendo os critérios que ajudaram a pôr em foco certos dados e ignorar outros, além de auxiliar a organizar os resultados.

Cada fonte de dado recebeu um tratamento diferenciado, tendo em vista o objetivo especifico de sua utilização ${ }^{13}$. Posteriormente, foi construído um diálogo entre os resultados das análises através de leitura transversal que promoveu a apreensão global da problemática estudada.

\footnotetext{
${ }^{13}$ Os objetivos de utilização das fontes de dados estão apresentados na tabela 3
} 
É importante salientar que o objetivo dessa leitura transversal é complexificar o estudo da temática sem a pretensão de tratar os dados por adição. Isso se deve ao reconhecimento do limite em confrontar informações tão diferentes, que foram coletadas e analisadas a partir de bases epistemológicas do mesmo modo diferentes.

\subsection{PROCEDIMENTOS ÉTICOS}

Esta pesquisa foi realizada mediante aprovação do Comitê de Ética da SMS de São Paulo e da Comissão de Ética para Análise de Projetos de Pesquisa do Hospital das Clínicas da Faculdade de Medicina da Universidade de São Paulo cujos termos estão presentes no Anexo 4 e 5 desta dissertação.

Todos os procedimentos de coleta de dados realizaram-se mediante leitura e assinatura do termo de consentimento livre esclarecido (anexo 6). 


\section{RESULTADOS}

Os resultados obtidos através da análise das diferentes fontes de dados dessa pesquisa ${ }^{14}$ foram sistematizados na forma de um estudo de caso, o qual será apresentado a partir de dois eixos, os quais sejam:

\section{SERVIÇO DA EASPPD}

Nesse tópico serão apresentados os resultados da análise do documento de implantação da EASPPD e do questionário de caracterização da equipe (Anexo 2). Esses dados combinados irão fornecer um panorama do serviço estudado a partir dos seguintes aspectos:

- O Cenário - Uma breve descrição do local onde o serviço está inserido.

- Os Atores - Descrição das características dos profissionais que integram a EASPPD estudada.

- O Roteiro - Apresentação do conceito do serviço.

\section{O SERVIÇO NA PERSPECTIVA DE SEUS ATORES:}

Nesse tópico será apresentado o resultado da análise das entrevistas realizadas com os trabalhadores da EASPPD.

\footnotetext{
${ }^{14}$ No capítulo 4 (método) foram apresentadas as diferentes fontes de dados usadas nessa pesquisa, bem como os objetivos da utilização de cada uma delas.
} 


\subsection{CONHECENDO O SERVIÇO DA EASPPD}

\subsubsection{O CENÁRIO}

A EASPPD estudada nessa pesquisa está inserida numa UBS localizada no distrito da Vila Curuçá, na zona leste da cidade de São Paulo. O distrito da Vila Curuçá, faz parte da supervisão técnica de saúde do Itaim Paulista que, por sua vez, pertence à Coordenadoria Regional de Saúde Leste da cidade de São Paulo.

A população dessa região está estimada em 146.482 habitantes com Índice de Desenvolvimento Humano $(\text { IDH })^{15}$ de $0,76516$.

Segundo Bousquat et al (2006), o distrito de vila Curuça está 100\% coberto pelo PSF através de oito UBS ${ }^{17}$. Todas essas unidades contam com o serviço de profissionais da EASPPD e têm como referência ambulatorial uma das unidades de saúde localizada na região que foi a UBS onde se instituiu o campo desta pesquisa.

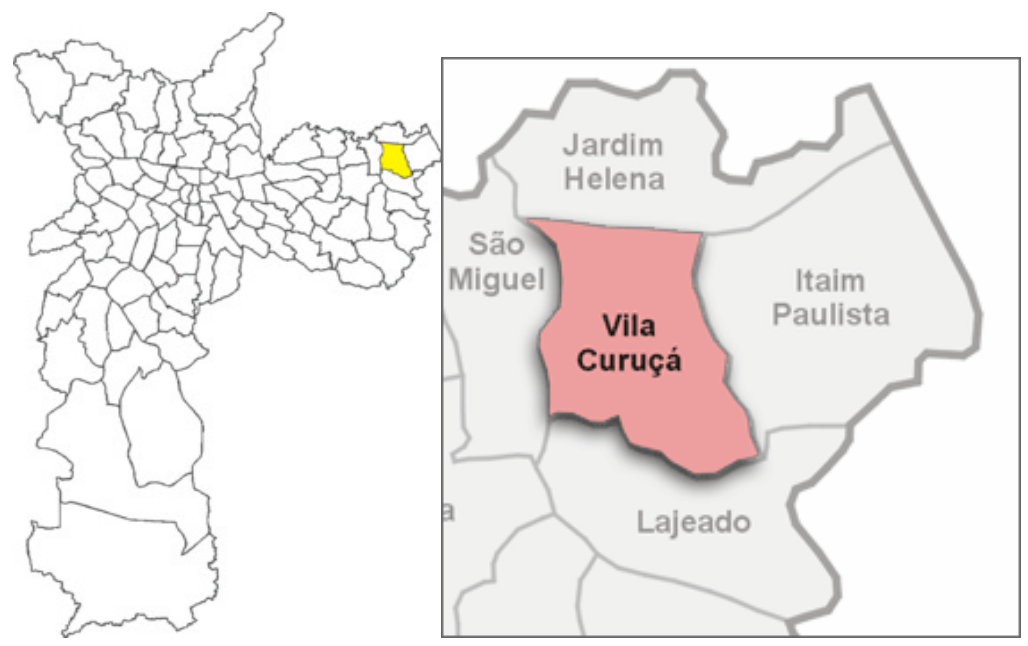

Figura 3. Localização do Distrito Paulistano de Vila Curuçá. (Adaptado de: http://pt.wikipedia.org/wiki/Vila Curu\%C3\%A7\%C3\%A1e http://www2.prefeitura.sp.gov.br/subprefeituras/spit/mapas/0003).

${ }^{15} \mathrm{O} I \mathrm{IDH}$ é uma medida comparativa da ONU que engloba três dimensões: riqueza, educação e esperança média de vida e que compreende scores de 0 - 1. Fonte: http://www.pnud.org.br/idh/. Consultado em 01.04.2008.

${ }^{16}$ Dados disponíveis em: http://www9.prefeitura.sp.gov.br/forms/estabelecimentos saude/index.php. Consultado em 10.05.2008.

${ }^{17}$ Fonte: http://www9.prefeitura.sp.gov.br/forms/estabelecimentos saude/index.php.Consultado em 15.04.2008 


\subsubsection{OS ATORES}

Os resultados apresentados aqui são oriundos, predominantemente, da análise dos dados das entrevistas e dos questionários (Anexo 2). A aplicação dos questionários teve o intuito de caracterizar os profissionais da equipes destacada como descrito a seguir:

No período da aplicação do questionário havia dez profissionais trabalhando na EASPPD, sendo seis fisioterapeutas, três fonoaudiólogos e um terapeuta ocupacional.

Todos os profissionais da equipe eram do sexo feminino com idade que variava entre vinte e sete e quarenta anos. Quanto ao tempo em que trabalham na EASPPD, quatro profissionais referiram trabalhar nesse serviço desde sua implantação (sete anos); um profissional referiu trabalhar a seis anos; quatro referiram trabalhar a quatro anos; e um referiu trabalhar a três anos.

Os profissionais dessa EASPPD tinham duas modalidades de inserção junto à UBS:

Os profissionais dessa EASPPD tinham duas modalidades de inserção junto a UBS.

- Como apoio às equipes de saúde da família sendo co-responsáveis pela população adscrita da UBS.

- Como serviço de referência ambulatorial em reabilitação para as demais equipes de saúde da família do distrito de Vila Curuçá. 
Esses dez profissionais estavam divididos em duplas que cobriam em média duas unidades do território e ainda atendiam os casos referenciados no ambulatório pelo menos uma vez por semana.

No que se refere à formação dos profissionais para atuação nesse serviço, seis profissionais afirmaram não ter formação específica para o trabalho na atenção primária. Outros três referiram contato com o tema na graduação por meio de disciplinas e/ou estágios e dois trabalhadores referiram aperfeiçoamento em nível de pós-graduação em áreas relacionada ao PSF.

\subsubsection{O ROTEIRO: O CONCEITO DO SERVIÇO}

Neste tópico será apresentado o resultado da análise do documento de implantação da EASPPD ${ }^{18}$. Tal análise teve como objetivo identificar o conceito do serviço pesquisado.

A definição do termo Conceito do Serviço foi apresentada e discutida no capítulo 2. No entanto, em função da importância dessa concepção para a construção desse trabalho e, também, para a sistematização dos dados que serão apresentados far-se-á uma retomada de sua definição:

O Conceito do Serviço é um conjunto de princípios que definem quais os valores serão entregues ao usuário explicitando os recursos mobilizados, pelos trabalhadores, para entregar o serviço proposto (Kingman - Brundage, 1993).

\footnotetext{
${ }^{18}$ O documento de implantação da EASPPD é denominado: Programa de atenção à saúde da pessoa portadora de deficiência e incapacidade no PSF/QUALIS - SP. Zona leste e sudeste do município de São Paulo (Rocha e Kretzer, 2000)
} 
Nessa direção, serão apresentados:

- Os objetivos do serviço

- O valor do serviço

- A operação do serviço

\subsubsection{OBJETIVOS DO SERVIÇO}

A Equipe de Atenção à Saúde da Pessoa Portadora de Deficiência foi criada, em 2000, para atuar junto ao projeto QUALIS que vigorava na cidade de São Paulo de forma similar ao Programa Saúde da Família instituído em demais regiões do país (Rocha e Kretzer, 2000; Fichino et al, 2008).

Os objetivos previstos para o serviço da EASPPD estão descritos no seu projeto de implantação (Rocha e Kretzer, 2000) como:

- Garantir atendimento das necessidades, gerais e específicas, advindas da deficiência por intermédio de ações no PSF, garantindo atenção à saúde, inclusive em outros níveis de complexidade, em consonância com os princípios do SUS.

- Estabelecer na atenção primária uma cultura que contemple a defesa dos direitos da pessoa com deficiência visando aumentar a participação social dessa população por meio de intervenções articuladas na prevenção de agravos e na promoção e assistência à saúde. 
Para alcançar esses objetivos algumas atribuições foram delegadas aos profissionais da EASPPD enumerados a seguir:

- Capacitação continuada das equipes de saúde da família para atendimento de necessidades das pessoas com deficiência, bem como a identificação de situações de risco e vulnerabilidade a que esta população está exposta.

- Atendimento domiciliar

- Referência técnica específica de reabilitação na Unidade Básica de Saúde.

- Concessão de próteses e órteses

- Elaboração de soluções simplificadas de reabilitação para domicílio e para comunidade.

- Elaboração de propostas e encaminhamento de ações junto das equipes de saúde da família visando diminuir desvantagens sociais e inclusão das pessoas com deficiência.

- Elaboração e implantação de normas e fluxos em um sistema de referência e contra-referência hierarquizado e regionalizado direcionado à população com deficiência.

- Elaboração e implantação de um subsistema de informação ambulatorial em reabilitação.

- Sensibilização, informação e orientação da comunidade e dos profissionais das equipes de saúde da família por meio da realização 
de oficinas, encontros técnicos e produção de material impresso e áudio visual.

- Capacitação de profissionais do QUALIS/PSF para ações de prevenção e reabilitação sobre os quadros de deficiência mais prevalentes na população adscrita por meio de curso de atualização e supervisão técnica.

- Construção de um campo de ensino e pesquisa para profissionais de reabilitação por meio de parcerias com universidades.

- Elaboração e implantação de instrumentos de acompanhamento e avaliação do projeto.

\subsubsection{VALOR}

O valor do serviço prestado pela EASPPD é o aumento da participação social dos indivíduos que usufruem deste serviço. Diante dos seus objetivos observa-se que o aumento na participação social pode ser obtido:

- Por meio do atendimento de demandas gerais e específicas da população com deficiência - Dessa forma, os profissionais da EASPPD podem favorecer a mobilidade de um usuário mediante a prescrição de um dispositivo de tecnologia assistiva adequado, como uma cadeira de rodas, que permitirá o acesso à escola, por exemplo. 
- Por meio do estabelecimento de uma cultura que contemple a defesa dos direitos da pessoa com deficiência - Nesta perspectiva ações dos profissionais da EASPPD que fomentem a mobilização da comunidade para solicitação de transporte adaptado circulando em determinado território podem favorecer a inclusão de pessoas com deficiência no mercado de trabalho. Além de garantir o direito de ir e vir das pessoas com deficiência.

\subsubsection{OPERAÇÃO}

A operação do serviço é a série de ações ou eventos que concorrem para entregar o serviço identificando seus recursos e processos (Johnston e Clark, 2002).

Nessa direção, a operação da EASPPD teve como proposta um modelo interdisciplinar de atuação, onde profissionais da EASPPD trabalham em conjunto com os profissionais da equipe de saúde da família no atendimento das necessidades da população com deficiência de maneira diferenciada já que a reabilitação ocorre de forma contextualizada, dentro de processos de inclusão e aumento da participação social de pessoas ou grupos vulneráveis (Rocha e Kretzer, 2000).

A população alvo desse serviço compreende pessoas de todas as faixas etárias, com todos os tipos de deficiência (sensorial, física, mental, múltiplas), e/ou incapacidades, em situação de exclusão social e de risco (Rocha et al, 2002). 
A equipe mínima prevista para o trabalho é composta de oito fisioterapeutas, cinco fonoaudiólogos e cinco terapeutas ocupacionais divididos em duplas responsáveis por até dez equipes de saúde da família. É importante salientar que o projeto de implantação da EASPPD prevê sua operação ajustada aos princípios do SUS com atividades integradas a programação geral das equipes de saúde da família (Rocha e Kretzer, 2000).

Todos os profissionais da EASPPD devem realizar atendimentos domiciliares e nas áreas de abrangência das UBS tendo o ambulatório de reabilitação como referência para os casos que demandem o uso de recursos de maior densidade tecnológica. O foco das ações desses profissionais deverá abranger além das pessoas com deficiência, suas famílias e comunidades.

Nesse contexto, a EASPPD atua em duas instâncias: Como apoio das equipes de saúde da família nas intervenções junto à população com deficiência e também como referência das UBS para os atendimentos específicos de reabilitação em casos que requeiram maior especificidade e/ou o uso de recursos de maior e densidade tecnológica (ambulatório).

Quanto à distribuição desse serviço, segundo Rocha e Kretzer (2000), cabe aos ACS detectar a população de pessoas com deficiência, sua determinação e classificação.

A partir desse levantamento feito pelos ACS as ações básicas de reabilitação são endereçadas aos familiares, ACS e aos profissionais das 
equipes de saúde da família sob supervisão da EASPPD. As intervenções mais específicas são executadas pelos profissionais de reabilitação em ambulatório especializado. Esse fluxo está ilustrado na figura 3

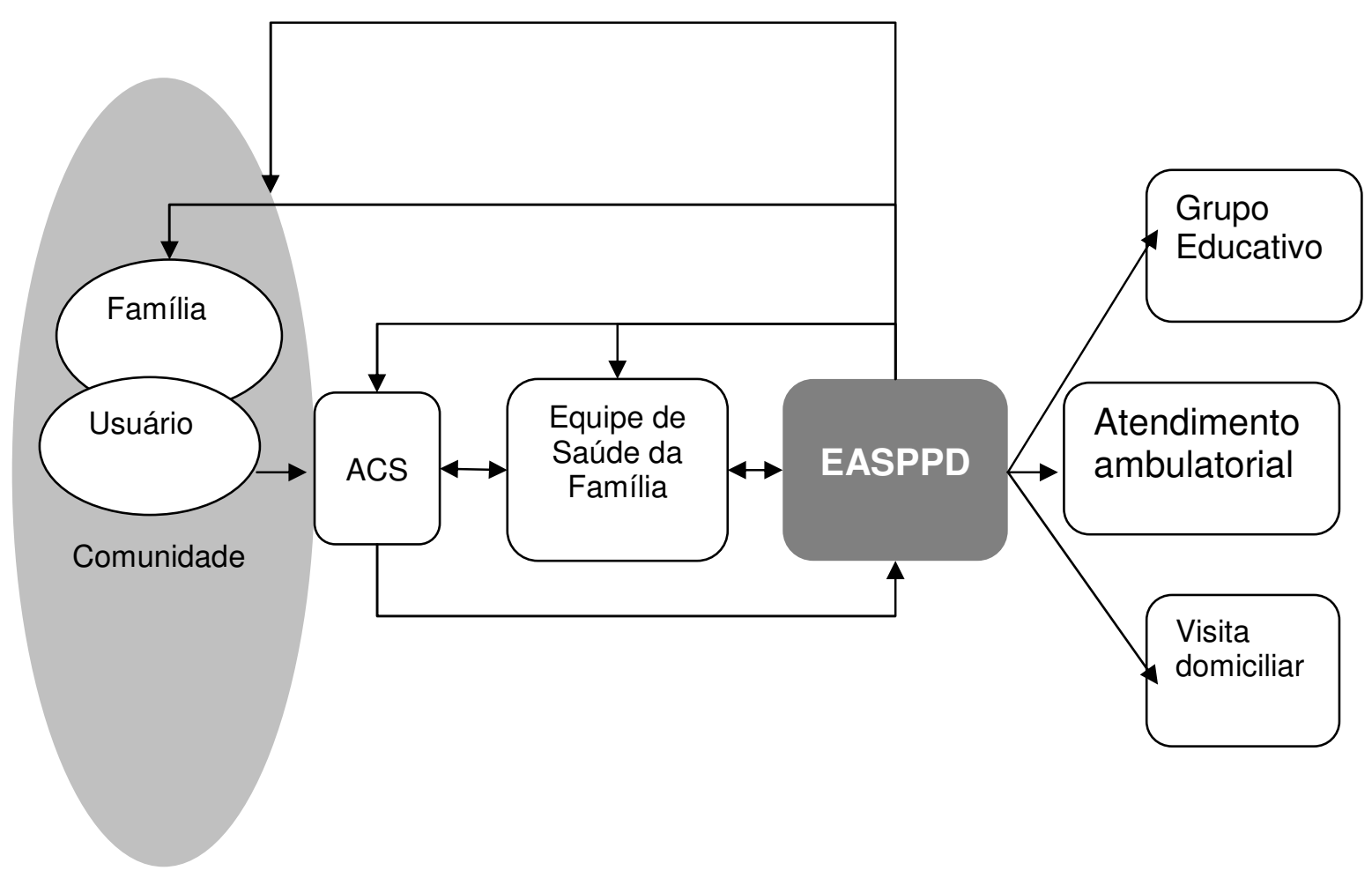

Figura 3. Fluxo de atendimento da EASPPD. (elaborado pelo autor)

A implantação do serviço da EASPPD foi planejada para acontecer nas seguintes etapas (Rocha e Kretzer, 2000):

1. Implantação do programa de reabilitação: Nessa etapa estavam previstas a seleção e contratação dos profissionais que integrariam a EASPPD, organização do fluxo de atendimento e ainda a elaboração de sub 
programas de reabilitação, bem como, dos protocolos de registro e o sub sistema de informação na rede.

2. Diagnóstico Situacional: Levantamento de dados referentes a atenção à saúde da pessoa com deficiência, bem como, das necessidades imediatas desse grupo populacional. Discussão da proposta do projeto junto às equipes de saúde da família.

3. Sensibilização: A sensibilização ocorreria junto das equipes de saúde da família e de pessoas da comunidade, por meio da realização de oficinas, que tinham o intuito de romper com estereótipos relacionados à pessoa com deficiência.

4. Capacitação de recursos humanos:

Referia-se à capacitação dos profissionais da EASPPD, da equipe de saúde da família e saúde bucal através da realização de cursos.

O projeto da EASPPD também previa a elaboração de material (manuais e vídeos) que servissem de apoio para as oficinas de sensibilização e cursos de capacitação.

6. Elaboração de um sub sistema de informação ambulatorial em reabilitação para registro dos procedimentos realizados de acordo com 0 Sistema de Informação Ambulatorial do SUS.

7. Elaboração e implantação de instrumentos de acompanhamento e avaliação do projeto.

No que se refere ao custeio do serviço foi previsto (Rocha e Kretzer, 2000):

6 Financiamento dos cursos e oficinas. 
$7 \quad$ Compra de material permanente e de consumo.

8 Provisão de salário, por um ano, para os profissionais contratados.

\subsection{O SERVIÇO NA PERSPECTIVA DE SEUS ATORES: ANÁLISE DO CONTEÚDO DAS ENTREVISTAS}

O depoimento dos profissionais da EASPPD permitiu explorar aspectos da organização do trabalho do serviço estudado sob a perspectiva dos trabalhadores de linha de frente.

Após a leitura minuciosa da transcrição das entrevistas, dois temas foram destacados por que coadunam com os objetivos desse estudo. Os temas em questão são: A dualidade do serviço e a Invisibilidade do trabalho.

Dualidade é entendida aqui como propriedade e/ou caráter duplo, e se expressa no serviço da EASPPD pela coexistência de duas racionalidades distintas dirigindo a operação do serviço. Essas duas racionalidades são oriundas do projeto de implantação da EASPPD que prevê o desenvolvimento de ações em dois níveis de atenção à saúde (atenção primária/PSF e ambulatório de reabilitação)

Esse caráter duplo do serviço parece dificultar a identificação e a avaliação do trabalho desenvolvido pelos profissionais da EASPPD. Os reflexos dessa questão na organização do trabalho apareceram no discurso 
dos trabalhadores do serviço e foram agrupados em uma categoria de análise denominada: Invisibilidade do Trabalho.

Vale ressaltar que os trechos dos depoimentos dos profissionais da EASPPD, transcritos ao longo desse tópico, estão identificados pela letra $E$ seguida de um número para identificar a origem desses dados.

\subsubsection{A DUALIDADE DO SERVIÇO}

O projeto do serviço da EASPPD previa que os profissionais de linha de frente desempenhassem funções ligadas, ao mesmo tempo, à atenção primária/PSF e ao ambulatório de reabilitação.

Diante dessas duas racionalidades, que orientam de forma concomitante o serviço da EASPPD, os trabalhadores identificaram que ao privilegiar a atenção a um grupo populacional específico - pessoas com deficiência - o projeto do serviço da EASPPD se afasta dos preceitos da atenção primária e conseqüentemente do PSF.

"A proposta é que seja pro deficiente, acaba desfocado porque não fica só pro deficiente. Isso é uma coisa que eu discordo da proposta. Eu acho que não deveria existir equipe de saúde do deficiente porque no serviço público não tem só deficiente, então tem que ser aberto pra todo mundo. Isso é uma coisa que me pega muito no projeto. Isso distancia muito".E1

Outra decorrência da dualidade do serviço da EASPPD, encontrada nos discursos dos trabalhadores, é o conflito existente entre as percepções que estes têm a respeito da natureza do serviço e as ações que desenvolvem na prática. 
Nessa direção, quando os trabalhadores falam a respeito das crenças sobre o trabalho que desempenham há o predomínio de referências sobre a atenção primária/PSF

"Eu faço saúde coletiva mesmo, eu sou atenção básica, visita domiciliar, eu gosto mesmo de trabalhar na comunidade, essa coisa muito clínica, muito fechada em consultório não é comigo". E2

"Tem esse atendimento junto da família a gente acaba conhecendo pelas reuniões de equipe com os agentes comunitários, pela própria proximidade mesmo, ta dentro da comunidade, perto da casa deles (...) a assessoria aí não é simplesmente clínica, vai além". E4

Os trabalhadores também referem preferir o trabalho calcado na atenção primária/PSF.

"Se tivesse que largar eu largava aqui (ambulatório), ficava na atenção básica mesmo". E7

No entanto, quando os profissionais descrevem o trabalho que realizam o atendimento ambulatorial este parece concorrer e se sobrepor às práticas típicas da atenção primária/PSF.

"O trabalho de prevenção, promoção não era pra ser segundo plano, mas acaba ficando, ou fica com menos espaço na agenda devido a demanda clínica que é muito grande" E1

"(...) não tem tido espaço a promoção dos grupos terapêuticos, porque acaba saindo. Mas mesmo naqueles espaços para grupos com bastante gente acabam ficando pra segundo plano (...). Acabam ficando pra segundo plano por que tem muita demanda clínica".E6

"Então, a gente desmarca os pacientes num dia do mês, por exemplo, e faz as atividades de promoção".E5 
Nessa direção, a patologia, o ambulatório, a intervenção especializada aparecem, muitas vezes, como elementos protagonistas no desenvolvimento das ações desses trabalhadores.

"Então, pode ser um grupo de artrose (...), tem os grupos de pacientes neurológicos, que acaba não tendo só paciente com seqüela de AVC, mas também com outro tipo de seqüela, como TCE (...)".E3

Maior demanda de criança com dificuldade escolar (...). Maior parte das vezes não é um problema fonoaudiológico é uma questão de aprendizagem mesmo, mas acaba caindo na fono.E1

"Geralmente a gente deixa um tema específico, por exemplo, coluna. Então as equipes direcionam pra esse grupo naquele dia determinado pra pacientes com queixa de coluna (...)".E5

Atendo 25 crianças e adultos com patologia mesmo. Então tem tipo troca articulatória, tem alguma coisa na voz, nódulo de corda vocal, a você, afasia, alguma coisa assim. E4

\subsubsection{A INVISIBILIDADE DO TRABALHO}

O conflito entre o que os profissionais pensam a respeito da natureza do seu trabalho e aquilo que realizam é fruto de um movimento pendular nos objetivos do serviço que, ora favorece ações na atenção primária/PSF, ora favorece ações no ambulatório de reabilitação.

Tal situação acaba afastando do PSF o trabalho da EASPPD implicando, na visão dos profissionais da reabilitação, na invisibilidade do trabalho que realizam.

"Não sei se o que a gente fez até hoje não teve esse impacto, que é o que dito pra gente: nosso trabalho não tem impacto".E4 
$\mathrm{Na}$ visão dos profissionais da EASPPD essa dificuldade de enxergar o trabalho realizado perpassa também a visão dos outros atores que integram o serviço os quais vêem no trabalho da reabilitação uma menor relevância. Isso pode ser retratado pela interferência durante os atendimentos dos profissionais de reabilitação.

- "E aqui eu tenho muita interferência também, gente que bate na porta, gente procurando outros funcionários, gente de outros postos que vem atrás de atendimentos".E2

“(...) ia fazer grupo na sala dos agentes, então toda hora tinha agente comunitário entrando, tinha administrativo entrando pra pegar prontuário, (...) era uma gritaria".E6

“(...) paciente bate na porta, agente bate, você tem pouco tempo pra fazer as coisas que você tem em mente". Parece que eu não estou trabalhando.E1

Ou ainda, pela dificuldade dos outros profissionais do PSF enxergarem que as ações da EASPPD que acontecem fora da unidade de saúde, com padrão diferente do atendimento ambulatorial, é parte do seu trabalho.

"Hoje eu estava numa reunião na OSEM, lotada de crianças, com educadores que não tem nenhuma noção do que é lidar com uma criança (...) eu fui fazer uma reunião com os responsáveis pra tentar uma intervenção. Cheguei aqui 9 h30 e o administrativo perguntou: onde você estava, tem um monte de paciente atrás de você".E1

“(...) terça tenho sempre uma reunião na comunidade, eu sempre vou chegar mais tarde, mas eu não estava na minha casa dormindo, descansando. Eu estava em outro lugar, resolvendo outra coisa. Para o pessoal da UBS parece que nesse dia eu cheguei atrasada".E3

"Quarta feira eu não vim porque estava na secretaria (SMS), eles estão preparando uma capacitação de voz pro ano que vem. Quando fui avisar no posto eles falaram: como você não vem quarta feira?". E4 
"Isso pega pra mim, você não tem reconhecimento. Se eu deixo de atender dez aqui pra atender mil lá fora, eles dão escândalo aqui no posto. Esses dez que eu deixei de atender dão escândalo e eu pareço uma má profissional. O que acontece lá fora dá a sensação que não é trabalho".E1

A dificuldade em enxergar e legitimar o trabalho da EASPPD ultrapassa as fronteiras do serviço e chega até os gestores. Estes, por sua vez, possuem, na perspectiva dos trabalhadores da EASPPD, ferramentas de gestão inadequadas para avaliar o serviço prestado e planejar os recursos necessários para a entrega do serviço.

Tal situação pode ser ilustrada pela dificuldade dos trabalhadores em enquadrar as suas ações nos instrumentos de registro designados pelos gestores.

"Eu olhei ali uns procedimentos que ou que a gente não fazia, ou que faltavam, então eu achei que eu ia conseguir mudar a tabela do SUS".E1

"Com quem que é que fala sobre essa tabela, com quem que a gente pode falar pra mudar essa tabela que não cabe tudo que a gente faz, a gente acaba faturando pouco porque a tabela não tem procedimento que a gente faz".E3

“(...) uma coisa que me incomodava na época porque eu tinha que preencher uma tabela que não condiz ao meu trabalho (...)".E7

Essa incongruência entre o que o gestor espera e o trabalho realizado acaba interferindo na avaliação dos resultados do serviço. Nesse sentido, os profissionais da EASPPD temem que seu trabalho seja avaliado de maneira inconsistente.

"Mas depende do que você acha que é efeito, se você acha que efeito é número de atendimento, é alta. (...) efeito é a qualidade, é bem estar? Apesar do nosso trabalho ser qualitativo sempre questionam a quantidade de atendimento que a gente faz".E2 
E às vezes para a pessoa nem é preciso um atendimento clínico, (...) às vezes é melhor, naquele momento, ela (paciente) ir ao forró, participar de um grupo de convivência. Mas esse tipo de encaminhamento não conta como atendimento, não entra na planilha".E1

A situação exposta deflagra que o processo do trabalho da EASPPD por não conseguir uma ancoragem sólida no seu projeto está exposto a mudanças constantes em sua organização. Para os trabalhadores isso se traduz em insegurança quanto ao futuro do trabalho.

"Realmente é uma grande interrogação, qual vai ser o futuro disso aqui. Eu não sei. (...) já teve uns perigos de fechar todo mundo num ambulatório falando que a gente só ia fazer atendimento clínico".E3

"A gente passou por vários momentos políticos complicados, a gente corria risco. Agora a gente está num momento desses, de ver o que vai acontecer. A gente não sabe".E6

“(...) quando a gente fala de mudança a gente nunca sabe se vai ser bom ou pra pior. (...) a gente fica um pouco assustado de um trabalho que vem vindo por aí, como é que vai ser"E1

“(...) está todo mundo de pé atrás com essas mudanças, com o que vai acontecer. (...) não sei como vai ser. A prefeitura olha e vê esse tanto de profissional numa área que é super carente de gente na reabilitação, eles querem fechar mesmo a gente no ambulatório". E5

As incongruências existentes entre o planejamento e a operação real do serviço da EASPPD terão conseqüências, destacadas em categorias a serem apresentadas adiante. 


\subsubsection{DIMENSIONAMENTO DA CAPACIDADE DO SERVIÇO}

Para os trabalhadores o serviço opera acima de sua capacidade. Desta forma, eles apontam que há uma incoerência no dimensionamento da quantidade de profissionais de reabilitação por equipe de saúde da família.

"Cada equipe tem cinco agentes comunitários, cada agente é responsável por duzentas e cinqüenta famílias. Cada família tem em média cinco pessoas, quando você faz a multiplicação dessas coisas você enlouquece, porque a gente tem que dar conta de cinco equipes".E1

Os profissionais da equipe nuclear estão oito horas, cinco dias por semana numa equipe só. A reabilitação está seis horas, às vezes duas ou três dias por semana, em um posto pra cobrir cinco equipes. É aí que o trabalho se perde, porque acaba sendo pouco o que a gente faz, pelo tanto que precisa.E7

Operar acima da capacidade do serviço imprime, em alguns trabalhadores, a sensação de impotência diante da grande demanda.

"Eu ganhei de presente uma caixa de prontuário, então eu tinha que dar conta daquela caixa de prontuário. No começo acha que vai dar conta de tudo aquilo, que na verdade não vai (...) no começo, você não almoça, não sai pra ir ao banheiro, porque você quer dar conta daquela demanda. Na verdade você não consegue". E1

Para outros trabalhadores, essa situação coloca em xeque o significado do trabalho. Assim, atender a demanda excessiva descaracteriza o serviço e atender se diferencia de trabalhar.

“(...) você começa a atender, atender, atender e nunca acaba. Então é assim, eu tinha a perspectiva de não atender muito, eu queria trabalhar muito, fazer muito".

Ao excesso de demanda os trabalhadores atribuem a dificuldade em alinhar suas ações com o trabalho das equipes de saúde da família. 
“(...) não tenho conseguido fazer reunião de equipe tem um bom tempo, uma vez ou outra acontece alguma coisa e você tem que ir à reunião. Mas é muito difícil por causa da agenda".E1

"Esse esquema de trabalho da gente é muito picado, uma vez por semana na unidade, não dá tempo de fazer reunião com a equipe. A proposta é fazer, mas não dá por causa da agenda".E5

"O processo de trabalho ta longe da proposta. A proposta é que seja multi, junto com o pessoal das equipes de saúde da família, mas não acontece porque a gente tem muito atendimento".E4

Essa situação agrava o distanciamento do trabalho da EASPPD do trabalho do PSF.

\subsubsection{Falta de recursos materiais para o trabalho.}

Outra conseqüência da falta de visibilidade do trabalho, verificada no discurso dos trabalhadores, refere-se à falta de recursos materiais para o desenvolvimento das ações da equipe de reabilitação.

"Assim as dificuldades maiores eram burocráticas. Em relação ao material, a precariedade das unidades, falta de material, falta de espaço, de dinheiro mesmo pra montar as coisas". E3

Nesse sentido os trabalhadores referem a falta de espaço físico para o desenvolvimento dos seus atendimentos.

“(...) eu não tinha sala, eu atendia na sala dos agentes comunitários, eu mudei meu horário (...) tive que trabalhar a tarde, porque de manhã os agentes usavam a sala pra fazer reuniões (...)".E1

"Alguns atendimentos eu cheguei a fazer na recepção, avaliação no corredor, na sala dos ACS (...)".E6 
(...) não é uma coisa que a gente tem salinha, suas coisas pra chegar e atender tranqüilo. As pessoas ficam no meio do caminho e você tem que pedir, por favor, pro outro sair da sala que você vai atender.E3

“(...) todo dia a gente chega e tem gente fazendo reunião na sala que estava destinada pra gente. Então, antes de começar o grupo eu tenho que sair negociando lugar com o pessoal da unidade".E2

Os trabalhadores da EASPPD também destacaram a escassez de material de consumo para realização de suas ações.

"Folha a gente traz, lápis a gente traz, tudo a gente traz, poucas coisas são fornecidas pelo posto, porque mal eles têm pra uso deles. Mal tem folha sulfite pra eles, quanto mais pra dar pra reabilitação fazer desenhos com as crianças".E1

"A gente teve que parar um dia de atendimento pra fazer um bazar pra comprar material que não tinha. A gente pegou o dinheiro e comprou coisas pra TO, pincel, tinta. E coisas pra fisio, como bolinha, teraband essas coisas"E1

“(...) teve uma compra de material quando a equipe começou e outra uns dois anos atrás, fora isso a gente se vira pra conseguir material".E5 


\section{DISCUSSÃO}

Os resultados apresentados no capítulo anterior permitiram conhecer aspectos do serviço da EASPPD a partir das idéias que nortearam sua implantação e, também, do ponto de vista de seus trabalhadores.

Essas duas perspectivas, ao serem confrontadas, favoreceram a observação de algumas questões, relativas à operacionalização do serviço estudado, que serão discutidas, neste tópico, sob a perspectiva do aporte teórico apresentado no capítulo 2 desta dissertação. 


\subsection{A OPERACIONALIZAÇÃO DO CONCEITO DO SERVIÇO DA EASPPD: A IDÉIA TRANSFORMADA EM AÇÃO}

O serviço prestado pela EASPPD se enquadra nas características de Serviço Profissional. A esse respeito, Quaggio (2007) afirma que diante da ampla autonomia de que os trabalhadores de linha de frente dispõe, nesse tipo de serviço, e da baixa especificidade das tarefas, o conceito do serviço é o único elemento que permanece constante entre a execução de um serviço para outro.

Portanto, a identificação do conceito do serviço foi o ponto de partida para as análises realizadas neste trabalho. Assim, buscou-se explicitar, por um lado, quais os princípios definem os valores a entregar para os usuários da EASPPD, e por outro, quais os recursos necessários para entregar o serviço proposto.

Para tal, foi verificado que o valor proposto no projeto de implantação da EASPPD é o aumento da participação social das pessoas com deficiência pela inclusão do atendimento de necessidades, gerais e específicas dessa população, num programa público de saúde, através do desmonte dos processos de exclusão.

Para entregar esse valor são elencadas várias ações, a serem desenvolvidas pelos trabalhadores da EASPPD, as quais, ao serem analisadas, demonstraram que o serviço requer que seus profissionais atuem em três esferas como detalhado na tabela 4. 


\begin{tabular}{|c|c|c|c|}
\hline $\begin{array}{c}\text { Racionalidade } \\
\text { do serviço }\end{array}$ & $\begin{array}{c}\text { Atendimento das } \\
\text { necessidades } \\
\text { gerais e específicas } \\
\text { da população com } \\
\text { deficiência }\end{array}$ & $\begin{array}{l}\text { formulação do } \\
\text { processo de trabalho } \\
\text { e de ferramentas de } \\
\text { gestão do serviço }\end{array}$ & $\begin{array}{l}\text { Desmonte dos } \\
\text { processos de } \\
\text { exclusão a que essa } \\
\text { população está } \\
\text { exposta }\end{array}$ \\
\hline 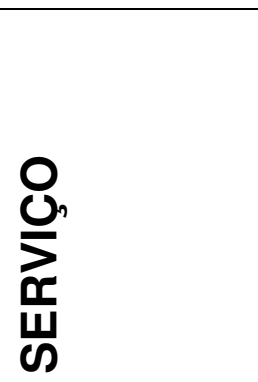 & $\begin{array}{c}\text { Capacitação } \\
\text { continuada das } \\
\text { Equipes de Saúde da } \\
\text { Família }\end{array}$ & $\begin{array}{c}\text { Elaboração e } \\
\text { implantação de normas } \\
\text { e fluxos para } \\
\text { atendimento da pessoa } \\
\text { com deficiência em um } \\
\text { sistema de referencia e } \\
\text { contra-referência } \\
\text { hierarquizado e } \\
\text { regionalizado. }\end{array}$ & $\begin{array}{l}\text { Sensibilização, da } \\
\text { comunidade e dos } \\
\text { profissionais das } \\
\text { equipes de saúde da } \\
\text { família para as } \\
\text { questões da população } \\
\text { com deficiência }\end{array}$ \\
\hline $\begin{array}{l}0 \\
0 \\
0 \\
\frac{0}{4} \\
\\
0 \\
0 \\
0 \\
0\end{array}$ & $\begin{array}{c}\text { Referência técnica de } \\
\text { reabilitação para a } \\
\text { UBS }\end{array}$ & $\begin{array}{c}\text { Elaboração e } \\
\text { implantação de um } \\
\text { sistema de informação } \\
\text { ambulatorial em } \\
\text { reabilitação }\end{array}$ & $\begin{array}{c}\text { Elaboração de } \\
\text { propostas e } \\
\text { encaminhamento de } \\
\text { ações junto com as } \\
\text { equipes de saúde da } \\
\text { família visando diminuir } \\
\text { desvantagens sociais e } \\
\text { inclusão da pessoa } \\
\text { com deficiência }\end{array}$ \\
\hline 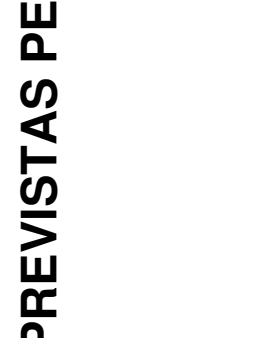 & $\begin{array}{l}\text { Concessão de } \\
\text { órteses e próteses }\end{array}$ & $\begin{array}{c}\text { Elaboração e } \\
\text { implantação de } \\
\text { instrumentos de } \\
\text { acompanhamento e } \\
\text { avaliação do projeto }\end{array}$ & $\begin{array}{l}\text { Fomento da } \\
\text { intersetorialidae }\end{array}$ \\
\hline ڤُ & $\begin{array}{l}\text { Atendimento } \\
\text { Domiciliar }\end{array}$ & & \\
\hline
\end{tabular}

Tabela 4. Detalhamento das ações da EASPPD nas três esferas do serviço. (elaborado pelo autor).

Essas três esferas de atuação, como demonstrado, operam segundo racionalidades distintas, por isso, em um primeiro momento, tal situação pareceu se constituir no cerne de incongruências na operação do serviço da EASPPD. 
Entretanto, as entrevistas realizadas com os trabalhadores do serviço apontaram que, por um lado, as ações de formulação do processo de trabalho e ferramentas de gestão, tal como planejadas, não foram desenvolvidas plenamente e, à época da coleta de dados desse trabalho, tais ações não ocorriam.

Por outro lado, os trabalhadores relataram que o destinatário das ações da EASPPD são os usuários da UBS, e de modo geral, as pessoas com deficiência não são prioridade nos atendimentos.

Os profissionais da EASPPD atribuem essa restrição ao atendimento da pessoa com deficiência a dificuldade que estas têm em chegar na UBS, e também, ao fato de estarem ligados a um programa de atenção primária, que é a porta de entrada do sistema de saúde, e por isso não devem restringir a assistência a um público alvo.

Corroborando com esse ponto de vista, Fichino et al (2008) aponta que, com o decorrer do tempo, por estar ligada ao PSF, a EASPPD ampliou seu campo de ação passando a atender qualquer usuário do PSF que demandasse atenção.

Desse modo, verificou-se que o usuário do serviço foi recaracterizado, e conseqüentemente, o valor a ser entregue também foi alterado, ocasionando uma fragilização no conceito desse serviço. Tal situação deflagrou a busca da identificação dos impactos desses achados na operação da EASPPD que serão apresentados adiante. 


\subsubsection{O SERVIÇO DA EASPPD NA LINHA DO TEMPO}

A implantação da EASPPD ocorre dentro da proposta QUALIS que apresentava em sua concepção serviços de retaguarda para as equipes nucleares de saúde da família em outros níveis de complexidade de atenção à saúde. Ambulatórios, laboratórios, equipes de saúde mental e casas de parto estavam acoplados à proposta de atenção prevista pelo QUALIS (Capistrano Filho, 2000).

Nesse contexto, quando projetado, o serviço da EASPPD estava em consonância com os fundamentos do QUALIS ao propor ações focadas numa população alvo (pessoas com deficiência) com ambulatórios para apoio nos casos de maior complexidade.

No entanto, quando houve a municipalização da saúde na cidade de São Paulo, em 2001, e as unidades do projeto QUALIS foram incorporadas à PSF houve um desalinhamento entre a proposta do serviço da EASPPD e os pressupostos do PSF, que não incluem a atenção específica à população com deficiência (Brasil, 2001; Brasil 2006).

Logo, apenas um ano após a implantação da EASPPD aconteceram profundas mudanças no cenário das políticas públicas de saúde na cidade de São Paulo. Como conseqüência dessa situação verificou-se que a continuidade do serviço da EASPPD foi viabilizada pelas instituições parceiras da SMS de São Paulo (Casa de Saúde Santa Marcelina e Fundação Zerbini). 
No que se refere aos gestores municipais, diante da fragilidade do conceito do serviço e da falta de referências nas políticas públicas em vigor, parece que houve, por parte desses, a dificuldade para identificar o papel que os profissionais dessa equipe ocupavam na rede de serviços.

Considerando que a existência de profissionais de reabilitação trabalhando junto ao PSF era uma experiência pioneira, na cidade de São Paulo, e que as ações da EASPPD foram projetadas para serem registradas e financiadas como atendimentos ambulatoriais, levar os profissionais da EASPPD para o ambulatório era uma tendência.

Essa situação, aliada a forma como o serviço foi projetado, gerou uma tensão entre as ações da EASPPD no PSF e no ambulatório de reabilitação. Observou-se que as intervenções concomitantes nesses dois níveis de atenção à saúde passaram a ser concorrentes ao invés de complementares o que foi destacado como a Dualidade do Serviço.

A Dualidade do Serviço dificulta a identificação e avaliação do trabalho realizado pelos profissionais da EASPPD, como demonstrado no capítulo de resultados,como a Invisibilidade do Trabalho.

\subsubsection{OPERAÇÃO}

No que se refere à operação do serviço a análise do projeto de implantação da EASPPD buscou identificar uma série de ações ou eventos que concorrem para entregar o serviço proposto (Voss, 2007). 
Nessa direção, verificou-se que o projeto de implantação da EASPPD dá ênfase aos resultados do serviço, mas não detalha quais recursos são necessários para entregá-lo.

Sobre o processo de trabalho o projeto indica que as ações da EASPPD devem ser baseadas em princípios da RBC ocorrendo em conformidade com o PSF, o que é uma proposta inovadora. Diante disso uma questão se faz presente: Como essa proposição se transforma em trabalho?

Os trabalhadores da EASPPD apontaram que o trabalho que realizam fica impregnado pelas ações no ambulatório de reabilitação, ou pelos atendimentos relacionados à especificidade de sua categoria profissional o que dificulta a realização de um trabalho compartilhado com as equipes do PSF.

No que se refere às ações de $\mathrm{RBC}$, as ações mais simples de reabilitação seriam desenvolvidas pelos profissionais das equipes de saúde da família sob a supervisão da EASPPD. Esse tipo de atividade não foi relatada pelos profissionais entrevistados. 


\section{CONSIDERAÇÕES FINAIS}

Esta pesquisa teve como objetivo analisar o processo de trabalho de um serviço de reabilitação da PSF da cidade de São Paulo. O estudo desenvolvido buscou alcançar esse objetivo e oferecer uma reflexão que contribua para a consolidação do campo de estudos de serviços públicos voltados a pessoa com deficiência.

A apresentação dos resultados abarcou a análise do conceito do serviço pesquisado, a partir de seu projeto de implantação, e sua confrontação com dados colhidos em campo, à luz do referencial teórico da gestão da operação de serviços, na busca de compreender como um serviço concebido em uma esfera conceitual é colocado em ação.

Esse trabalho favoreceu a apreensão das seguintes questões:

A criação da EASPPD foi significativa, pois ao incluir a equipe de reabilitação no PSF contemplou uma população que historicamente tinha uma inserção limitada nas políticas públicas de saúde, em especial na APS.

Isso foi possível pela adoção de um resultado focado na diminuição da incapacidade e no aumento da participação social que se constrói a partir de ações de baixa densidade tecnológica e alta complexidade, para atender necessidades de saúde da população com deficiência que são diretamente ligadas a APS ou que apresentem acesso restrito em serviços tradicionais de reabilitação.

No entanto, é importante lembrar que experiências de reabilitação na APS, e em especial junto ao PSF, estão em construção e apresentam 
fragilidades que ao serem discutidas poderão ajudar a aprimorar a implantação de serviços correlatos, bem como, fortalecer as experiências em curso.

Nesse sentido, alguns atributos críticos da operação do serviço da EASPPD merecem ser destacados:

1. O deslocamento das ações da EASPPD para aumento da participação e atividade dos indivíduos visando à redução de desvantagens oriundas de quadros de deficiência aliado às premissas da APS, como promoção da saúde e prevenção de agravos, implica em resultados mais intangíveis o que acarreta em uma dificuldade de apreensão dos recursos mobilizados para entregar o serviço.

Esse quadro apresenta como conseqüência incongruências entre o que os gestores esperam e planejam para o serviço e sua operação cotidiana, já que o dimensionamento das necessidades será realizado a partir de parâmetros que não retratam o trabalho que é realizado de fato.

2. A baixa especificidade e a grande autonomia, presente em serviços profissionais, como o da EASPPD, têm no conceito de serviço o único elemento do projeto que deve manter-se constante na entrega do serviço para o usuário (Quaggio, 2007).

No entanto, se verificou neste estudo que o conceito do serviço da EASPPD não foi consolidado em decorrência das modificações das políticas públicas de saúde que ancoravam essa experiência e, também, pela insuficiência do arcabouço teórico do seu projeto de implantação para 
legitimar parte das ações previstas para o serviço como, por exemplo, o ambulatório de reabilitação acoplado a atenção básica.

Essa situação teve reflexos:

a. No trabalho na linha de frente: Pela fluidificação do conceito do serviço o trabalhador passa a elaborar suas ações a partir de estratégias individuais ou de demandas pontuais se remetendo pouco aos pressupostos que fundamentam o serviço.

b. Na experiência do usuário: O usuário tem dificuldade de alinhar o que está sendo oferecido pelo serviço da EASPPD e suas expectativas que se baseiam, na maioria das vezes, nas suas experiências pregressas. Desse modo, mais uma vez a falta de solidez do conceito do serviço aprofunda as incoerências existentes entre o serviço oferecido pela EASPPD e o esperado pelos seus usuários.

Frente a essas constatações algumas considerações a respeito da organização do processo de trabalho da EASPPPD

O hiato que existe entre a operação e o conceito precisa ser preenchido em duas vias uma aproximando as proposições teóricas presentes no conceito do serviço da realidade cotidiana de quem desempenha o trabalho e na direção oposta reforçando as premissas do projeto pelo refinamento e incorporação dessas pelos profissionais de linha de frente e gestores. 


\section{REFERÊNCIAS BIBLIOGRÁFICAS}

Almeida, M. C. O cotidiano da pessoa deficiente: Reflexos e reflexões sobre reabilitação. Rev. Ter. Ocup. Univ. de São Paulo. São Paulo, 1997; 8 (2/3) p 81-86.

Almeida, M. C. Saúde e reabilitação de pessoas com deficiência: politicas e modelos assistenciais [tese]. Campinas: Faculdade de Ciências Médicas, Universidade Estadual de Campinas, 2000

Almeida, M. C. Campos, G. W. S. Políticas e modelos assistenciais em saúde e reabilitação de pessoas portadoras de deficiência no Brasil: análise de proposições desenvolvidas nas duas últimas décadas. Rev. Ter. Ocup. Univ. de São Paulo. São Paulo, 2002; 13 (3) p 118-26.

Almeida, M. C.; Tissi, M C.; Oliver, F. C. Deficiência e Atenção Primária em Saúde: do conhecimento à invenção. Rev. Ter. Ocup. Univ. de São Paulo, São Paulo, 2000; 11 (1) p. 35-44.

Almeida, M. C.; Oliver, F. C. Abordagens territoriais e comunitárias em Reabilitação de Pessoas com Deficiências: fundamentos para a terapia ocupacional. In: Bartolotti C.C.; Del Carlo M. M. R. (Organizadores). Terapia Ocupacional no Brasil: tendências e perspectivas. 1a. ed. São Paulo: Plexus Editora, 2001, p. 29-47.

Alves, S. V. Um modelo de educação em saúde para o Programa Saúde da Família: pela integralidade da atenção e reorientação do modelo assistencial. Interface - Comunic. Saúde, Educ. Botucatu, 2004-2005; 9 (16) p.39-52, set.2004/fev.2005

Bousquat, A.; Cohn, A. A.; Elias, P. E. Implantação do Programa Saúde da Família e exclusão sócio-espacial no município de São Paulo, Brasil. Cad. Saúde Pública, Rio de Janeiro, 2006, 22(9) p.1935-1943.

Bowen J. e Ford R. C. Managing Services Organizations: Does have a thing make a difference? Journal of Management, 2002, 28(3) 447-469 . 
Brasil. Ministério da Saúde. Secretaria de Assistência à Saúde. Atenção à pessoa portadora de deficiência no Sistema Único de Saúde - Planejamento e Organização de serviços. Brasília: Ministério da Saúde; 1995.

Brasil. Ministério da Saúde, Lei 8080 de 19 de Setembro de 1990, Brasília, 1990

Brasil. Ministério da saúde. Secretaria executiva. Programa Saúde da Família - PSF. Brasília: Ministério da Saúde; 2001.

Brasil. Ministério da Saúde. Secretaria de Assistência à saúde. Manual de Legislação em Saúde da Pessoa Portadora de Deficiência. Brasília. Ministério da Saúde 2003.

Brasil. Ministério da saúde, Portaria 1.065/GM de 04 de julho de 2005.

Brasil. Ministério da Saúde. Política Nacional de Atenção Básica. Brasília DF, 2006a Disponível em:

http://dtr2004.saude.gov.br/dab/legislacao/portaria 6482803 2006.pdf.

Brasil. Ministério da Saúde. Secretaria de atenção a saúde, Departamento de ações estratégicas. A pessoa com deficiência e o Sistema ùnico de Saúde. Brasília: Ministério da Saúde, 2006b.

Campos, G. W. S. O anti-taylor: sobre a invenção de um método para cogovernar instituições de saúde produzindo liberdade e compromisso. Cad. Saúde Pública. 1998; 14 (4) p.863-870.

Campos, G. W. S. Subjetividade e administração de pessoal: Considerações sobre a gestão do trabalho em equipes de saúde. In: Merhy, E. E.; Onocko R. (organizadores) Agir em saúde um desafio para o público. 3 Ed. São Paulo. Hucitec, 2007a.

Campos G. W. S. Reforma política e sanitária: a sustentabilidade do SUS em questão? Ciência e Saúde Coletiva. 2007; 12 (2) p. 301-306.

Capistrano Filho, D. O programa de saúde da Família em São Paulo. Rev. Estud. Av.1999; 13(35); p. 89-100. 
Cavalcante, M. G. S.; Sammico, I.; Frias, P. G.; Vidal, S. A. Análise de implantação das áreas estratégicas da Atenção Básica nas Equipes de Saúde da Família em município da região metropolitana do nordeste brasileiro Rev. Bras. Saúde Matern. Infant., Recife, 2006, 6 (4) p. 437-445.

Capozzolo, A. A. No olho do furacão: trabalho médico e o programa saúde da família [Tese]. Campinas, 2003. Faculdade de Ciências Médicas da UNICAMP.

Conill, E. M. Ensaio histórico-conceitual sobre a Atenção Primária à Saúde: desafios para a organização de serviços básicos e da Estratégia Saúde da Família em centros urbanos no Brasil. Cad. Saúde Pública 2008, 24, (1), p. 7-16.

Derani, C. Privatizações e Serviços Públicos: as ações do Estado na produção econômica. São Paulo: Editora Max Limonad, 2002.

Di Nubilla, H. B. V.; Buchala, C. M. O papel das classificações da OMS CID e CIF nas definições de deficiência e incapacidade. Rev Bras Epidemiol 2008; $11(2): 324-35$

Elias, P. E.; Bousquat, A.; Nakamura, E.; Cohn, A. A implantação do Programa de Saúde da Família na metrópole paulista 2001-2003. Resultado da primeira fase da pesquisa avaliação e construção de indicadores para 0 monitoramento da implantação do programa de saúde da família no município de são paulo, financiada pela FAPESP, no Edital de Políticas Públicas.MIMEO. São Paulo, 2005.

Farias, N., Buchalla, C. M. A Classificação Internacional de Funcionalidade, Incapacidade e Saúde da Organização Mundial da Saúde: Conceitos, Usos e Perspectivas. Rev Bras Epidemiol 2005; 8(2): p. 187-193

FICHINO, S. N; SANTOS, A. F; CROCCIA, M; NARDI, D. V; RESENDE, M. W. G. O Programa Saúde do Deficiente Reabilitação - Casa de Saúde Santa Marcelina Prefeitura do Município de São Paulo. In: Ir. Monique Marie M. Bourget. (Org.). Estratégia Saúde da Família: A experiência da Equipe de Reabilitação. São Paulo: Martinari, 2008, p. 29-42.

Goldbaum M; Gianini R. J.; Novaes H. M. D; César C. L. G. Utilização de serviços de saúde em áreas cobertas pelo programa saúde da família (Qualis) no Município de São Paulo. Rev. Saúde Pública. 2005; 39(1);90-99. 
Gummerson, E. Service management: na evaluation and yhe future. International Journal of Service Industry Management, v.5, n.1 p.77, 1994

Ho, D. C.; OLIVER, F. C. Terapia ocupacional e saúde da pessoa com deficiência na Secretaria Municipal de Saúde: uma discussão sobre dez anos de sua incorporação. Revista de Terapia Ocupacional da Universidade de São Paulo, São Paulo, v. 16, n. 3, p. 107-116, 2005.

Jardim T. A. Morar e trabalhar na comunidade. a realidade do agentes comunitários de saúde. São Paulo. Faculdade de Medicina, Universidade de São Paulo [Dissertação]. 2007.

Kingman-Brundage, J; George, W; Bowen, D. Service Logic: achieving service system integration. International Journal of Service Industry Management 1995; 6 (4) p. 20-39.

Lancman S. et al. O trabalhar no Programa Saúde da Família: Um estudo em Psicodinâmica do Trabalho. In: Viana, A. L. (coordenador). Cadernos de Atencão Básica: Inquérito com usuários e profissionais, percepção dos gestores e estudos sobre o trabalho no PSF. São Paulo. Centro de Estudos de Cultura Contemporânea. 2006.

Lovelock, C. H. Services marketing.4th Ed. Upper Saddle River, NJ: Prentice Hall. 2000.

Magalhães R. e Senna M. C. M. Local implementation of the Family Health Program in Brazil. Cad. Saúde Pública, Rio de Janeiro, 206, 22(12) p. 25492559.

Merhy, E. E.; Franco T. B. Por uma Composição Técnica do Trabalho em Saúde centrada no campo relacional e nas tecnologias leves. Apontando mudanças para os modelos tecnoassistenciais. Saúde em Debate. 2003, 27 p. $316-323$

Merhy, E. E. O conhecer militante d sujeito implicado: o desafio de reconhecê-lo como saber válido. In: Franco, T. B.; Peres, M. A. a. (organizadores). Acolher Chapecó. Uma experiência de mudança do modelo assistencial com base no processo de trabalho. 1 ed. São Paulo. Hucitec, 2004, p. 21-45.

Merhy E. E. Onocko, R. (organizadores) Agir em saúde um desafio para o público. 3 Ed. São Paulo. Hucitec, 2007. 
Merhy, E. E. Em busca do tempo perdido: a micro política do trabalho vivo em saúde. In: Agir em saúde um desafio para o público. $3 \mathrm{Ed}$. São Paulo. Hucitec, 2007 p.51-112

Nallin, A. Reabilitação em instituição - Suas razões e procedimentos: Análise de representação no discurso [Dissertação]. São Paulo: Instituto de Psicologia da Universidade de São Paulo; 1992.

Oliver F. C. Saúde mental e saúde da pessoa portadora de deficiência: estudo da incorporação da assistência nos serviços municipais da Administração Regional de Saúde São Miguel (1989-1995) [Tese]. São Paulo: Faculdade de Saúde Pública da Universidade de São Paulo; 1998.

Oliver, F.C.; Almeida, M.C.; TIssi, M. C.; Castro, L. H.; Formagio, S. Reabilitação Baseada na comunidade - discutindo estratégias de ação no contexto sociocultural. Rev. Ter. Ocup. Univ. São Paulo. 1999; 10 (1) p 1-10.

Oliver, F.C. Ghirardi, M. I. G. Almeida, M. C. Tissi, M. C. Aoki, M. Reabilitação no território: Construindo a participação na vida social. Rev. Ter. Ocup. Univ. São Paulo. 2001; 12 (1/3) p.15-22.

Oliver, F.C.; Aoki, M; TIssi M. C.; Nicolau, S. M. Reabilitação com ênfase no território - Jardim D’Abril e Jardim Boa vista no município de São Paulo. Rev. Ter . Ocup. Univ. São Paulo. 2003; 14 (3) p 140-145.

Organização das Nações Unidas. Programa de Ação Munidal para Pessoas Deficientes - 1982. Disponível em: www.cedipop.org.br/w6pam.htm.

Quaggio, F. M.; Silva, M. T.; Sznelwar, L. I. Mascia, F. L. Contribuições da Gestão de Serviços para os Serviços Públicos: uma análise dos serviços de atenção básica à saúde. Apresentado no XXV ENEGEP. Porto Alegre, RS, Brasil, 2005.

Quaggio F. M. Contribuições para o modelo de desenvolvimento de novos serviços: um estudo de caso em serviços de atenção básica à saúde [Dissertação]. São Paulo: Escola Politécnica da Universidade de São Paulo; 2007. 
Ramminger, T. Trabalhadores de saúde mental: reforma psiquiátrica, saúde do trabalhador e modos de subjetivação nos serviços de saúde mental. 1 Ed. Santa Cruz do Sul. EDUNISC 2006.

Rocha, E. F. Corpo deficiente: um desvio da norma? Rev. Ter. Ocup. Univ. de São Paulo, 1997; 2 p 182-187

Rocha, E. F. Kretzer, M. R. Programa de atenção à saúde da pessoa portadora de deficiência e incapacidade no PSF/QUALIS - SP. Zona leste e sudeste do município de São Paulo [mimeo]. 2000. Projeto técnico aprovado e implantado pela secretaria de Saúde do Estado de São Paulo.

Rocha, E. F. Shimizu, P. N. Barrales, L. M. Estágio de Terapia Ocupacional no Programa de Saúde da Família: reflexões sobre uma parceria didáticoassistencial entre o REATA/USP e o PSF/QUALIS. Rev. Ter. Ocup. Univ. São Paulo. 2002; 13 (3) p. 104-110

Rosa, W. A. G. L'Abate, R.C. Programa de saúde da família: a construção de um novo modelo de assistência. Rev. Latino Am. De Enfermagem. Ribeirão Preto, 2005,13 (6) p 1027-34.

Sampaio, R. F. et al. Aplicação da classificação internacional de funcionalidade, incapacidade e saúde (cif) na prática Clínica do fisioterapeuta. Rev. bras. Fisioter, 2005, 9(2) p 129-136

Santos, R. M. B. Projeto Qualidade Integral em Saúde (QUALIS): relato de uma experiência (abril de 1996 a junho de 1999) [dissertação]. São Paulo: Faculdade de Saúde Pública, Universidade de São Paulo; 2001

Silva, M. T. et al. Análise da organização do trabalho no Programa Saúde da Família. In: Viana, A. L. (coordenador). Cadernos de Atencão Básica: Inquérito com usuários e profissionais, percepção dos gestores e estudos sobre o trabalho no PSF. São Paulo. Centro de Estudos de Cultura Contemporânea. 2006

Silva M. T.; Salomao, S.; Alonso, C. M. C; Matsubara, S.; Freitas, E. T.; Gomes, C. E. S.; Cípulo, G.; Relatório de Análise Organizacional. In: Transformação do Modelo de Atenção Pública em Saúde Mental e seus efeitos no processo de trabalho e na saúde mental de seus trabalhadores. Relatório final da pesquisa financiada pelo CNPq Processo 554503/2005-0 MIMEO. São Paulo, 2007 
Silvestro R. Positioning services along the volum- variety diagonal. The contingencies of services design, control and improvement. International Journal of Operations \& Production Management, 1999, 19 (4) p. 399-420.

Starfield, B. Atenção primária: equilíbrio entre necessidades de saúde, serviços e tecnologia. Brasília: UNESCO, Ministério da Saúde, 2002.

Szenlwar, L. I. e Issy J. A. Programa Saúde da Família: Pontos de vista da organização de serviços, da ergonomia e da psicodinâmica do trabalho. In: Viana, A. L. (coordenador). Cadernos de Atenção Básica: Inquérito com usuários e profissionais, percepção dos gestores e estudos sobre o trabalho no PSF. São Paulo. Centro de Estudos de Cultura Contemporânea. 2006

Teixeira C. F. Modelos de atenção voltados para qualidade, efetividade, equidade e necessidades prioritárias de saúde. Caderno da 11a Conferência Nacional de Saúde 2000 (Modelos tecnoassistenciais). Brasília, 2000.

Voss C.; TsiKriktsis, N.; Frohlich, M. Case Research in operations management. International Journal of Operations \& Production Management.2002, 22(2) p. 195-219.

Voss C.; Zommerdijk L. Innovation in Experiential services - An empirical view. In: DTI (ed). Innovation inServices. London: DTI. pp.97-134. Disponível em: http://www.dti.gov.uk/files/file39965.pdf.

Yin R. K. Estudo de Caso: planejamento e métodos. 2 Ed. Porto Alegre: Bookman, 2003.

Zarifian, P. Valor, Organização e Competência na produção de serviço.

In: Salerno, M. S. (organizador) Relação de serviço: produção e avaliação. 1 Ed. São Paulo: SENAC, 2001a

Zarifian P. Objetivo competência por uma nova lógica. 1 Ed. São Paulo: Atlas, 2001b.

Zarifian P. O Modelo da Competência: Trajetória histórica, desafios atuais e propostas. 1 Ed. São Paulo: SENAC, 2003. 